Rakenteiden Mekaniikka (Journal of Structural Mechanics)

Vol. 54, No. 4, 2021, pp. 143-171

http://rakenteidenmekaniikka.journal.fi

https://doi.org/10.23998/rm.107868

(C) 2021 The Authors

Open access under the license CC BY 4.0

\title{
CLT beam analysis using classical elastic theory of layered beams
}

\author{
Markku Heinisuo ${ }^{1}$, Sami Pajunen
}

Summary The classical elastic theory of layered beams is used for the analysis of crosslaminated timber (CLT) beams. A brief introduction of the theory is given and followed by examples. The theory of layered beams offers a widely studied and well-established method for the analysis the CLT beams including displacements and stresses of each layer of the beam. It is shown that the theoretical basis of the widely used Shear Analogy is the same as the theoretical basis of the theory of layered beams. The results are compared to test results and to results of the finite element calculations. It is seen that the deflections and strains are in $10 \%$ fractals in mean in the considered cases. The theory of layered beams seems to be suitable method in the analysis of the CLT beams at the elastic phase.

Key words: cross-laminated timber, theory of layered beams, CLT beam

Received: 29 April 2021. Accepted: 21 December 2021. Published online: 22 December 2021.

\section{Introduction}

Cross-laminated timber (CLT) is an innovative engineering wooden panel, made of at least three layers of strength graded boards (typically C14-C30) that are laminated by gluing with structural adhesives. Since CLT has illustrated its potentials and competences of using as dominant building materials for mid- and high-rise timber buildings, a series of studies have been focused on the structural behaviour of CLT structures during last 30 years.

The grain directions of all the boards in every layer are the same. Thicknesses and orientations of the layers of CLT can vary, but typically the grain directions of adjacent layers are orthogonal. There can be 3-9 layers and thicknesses of the layers can vary in the range $20-60 \mathrm{~mm}$. The total thickness of the product varies in the range $60-500 \mathrm{~mm}$ and CLT panels can be up to $4.8 \mathrm{~m}$ wide and up to $30 \mathrm{~m}$ long Ref. [4]. Each CLT manufacturer has own standard thicknesses and strength classes. Similarly, the crosssection and the orientation of its layers differ from manufacturer to manufacturer.

${ }^{1}$ Corresponding author: markku.heinisuo@tuni.fi 
Before 1990's some constructions were completed with CLT, especially in relation to timber bridge decks. In 1990's, some intensive research activities regarding CLT started in Graz, Austria Ref. [5], see also Ref. [27]. Both references include an excellent state-of-the-art of CLT structures with a comprehensive list of references. The first European standard for CLT was introduced in 2015, Ref. [17]. It regulates production and construction, but a uniform design procedure is lacking. The design procedure can be found in some national annexes to the European standard, Refs. [14], [50], although it is not included in the European standard for timber structures, Ref. [16]. Engineers use various technical regulations and manufacture-issued specifications for CLT-related calculations. Examples of regulations are Refs. [43], [48], as well as manuals for Canadian, Ref. [19], US, Ref. [28] and Scandinavian, Ref. [4] markets.

CLT panels act in-plane or out-of-plane or both. In this study the out-of-plane loading is considered restricting to the beams in the elastic phase. The layers of the cross-section resist bending loads with axial and shear stresses. The stresses are distributed to the layers based on the shear moduli and the Young's moduli of the layers. The glue is supposed to be as strong and as ductile as the layers and no slip is assumed at the glue. The most important moduli in the beam design are the Young's modulus parallel to the grain direction $E_{0}$, the Young's modulus perpendicular to the grain direction $E_{90}$, the shear modulus $G_{0}$ (Longitudinal/Radial LR, Ref. [21]) and the so called rolling shear modulus $G_{90}$ (Tangential/Radial TR). The rolling shear describes one critical failure mode of the wood. The shear strength and modulus of the cross-layer where the grain direction of the layer is perpendicular to the beam axis, is weak in tangential/radial (TR) plane. The modulus $G_{90}$ and the rolling shear strength have been identified as key issues in the CLT panel for out-of-plane bending applications, Ref. [2].

It was shown in Ref. [44] for red oak, Douglas-fir and western hemlock species, that there were no significant differences between Young's moduli in tension and in compression. There were also no indications that Young's moduli were function of either stress level or strain rate. Differences between dynamic flexural moduli were less than 3\% from static tensile moduli. The measurement of the Young's modulus can be completed by static tension or compression and in bending using the dynamic test as described in Ref. [30]. Based on this and similar studies for graded timbers, same Young's modulus is given for compression, tension and bending, depending on the grain direction, e.g., $E_{0}$ and $E_{90}$. According to Ref. [15], the Young's modulus of the layer must be set zero if the boards are not edge glued. Totally different values of tensile, compressive and bending Young's moduli are reported in Ref. [29], in which the tensile modulus was two times greater than the compressive modulus of the same specimen. The bending modulus was between those two.

In Ref. [18] are given approximations for the shear moduli: $G_{0}=E_{0} / 16$ and $G_{90}=$ $G_{0} / 10$. In Ref. [4] is given for the frequently used grade C24 the value $G_{90}=50 \mathrm{MPa}$. The rolling shear strength and modulus have been defined based on bending tests and based on compression shear tests of Ref. [42]. In the bending tests the shear strains of the cross-layers are measured using strain gauges. The compression shear test is defined in Ref. [17]. In Ref. [42] were tested Canadian hemlock CLT panels. The mean rolling shear strengths and moduli were in the bending tests $1.57 \mathrm{MPa}$ (standard deviation SD = $0.07 \mathrm{MPa})$ and $234 \mathrm{MPa}(\mathrm{SD}=14.97 \mathrm{MPa})$. In the compression shear tests the results 
were 1.28 $\mathrm{MPa}(\mathrm{SD}=0.20 \mathrm{MPa})$ and $53.13 \mathrm{MPa}(\mathrm{SD}=19.13 \mathrm{MPa})$. The most possible reason which has an obvious impact on the rolling shear strength is a size effect, Ref. [32]. The rolling shear modulus, the results calculated by strain measurements at the edge of shear constant areas in the bending tests, are more than four times of the value from the compression shear tests, $234 \mathrm{MPa}$ and $53.13 \mathrm{MPa}$. Apparently, the rolling shear modulus of small compression shear specimens is much lower than that of a structural element. Apart from the size effects, the possible reason for the large difference is, that the adjacent parts of the testing area in bending shear specimens make large contributions to the bearing shear loads, while the specimen in the compression shear test has no "helpers", Ref. [42].

CLT beams have been analysed using general purpose finite element (FE) programs. The FE-models have been done with FE-shell model in two dimensions, Ref. [35], FE-shell model in three dimensions, Ref. [34], and many more, see e.g. Ref. [1]. In this study analytical methods are considered. Various theories have been proposed for the analysis of CLT beams. The key issue of the theories is, including the FE-models, how the shear deformations of the cross-layers are considered? Three methods are widely used in bending problems: Gamma Method, Ref. [36], Shear Analogy, Ref. [31] and Timoshenko Method, Ref. [47]. A comparison of these theories outlining their individual advantages and disadvantages is given in Ref. [3].

The Gamma Method is probably the most common approach in Europe, and it is given in Ref. [16] and in Ref. [4]. The Gamma Method can be implemented with the Euler-Bernoulli beam element as no shear deformations are considered, but it takes into account them indirectly by calculating the effective bending stiffness based on the efficiency of the connection between the longitudinal layers. This connection is provided by the shear stiffness of the cross-layers. The effective bending stiffness is calculated by summing the individual bending stiffnesses of the layers and adding the Steiner term with a factor Gamma. The factor Gamma includes the effective length, that is the length of the beam between two zero-moment points, inflection points. This means that the use of the Gamma Method means an iterative approach, because the moment distribution may be dependent on the bending stiffness. It is also limited to sinusoidal and parabolic moment distributions in Ref. [16].

The Shear Analogy and the Timoshenko Method can be applied in case of any number of layers and for multi-span beams with arbitrary loads. The Shear Analogy is motivated by considering two separated beams, which are coupled to deflect the same amount, Ref. [3]. This leads to a group of differential equations. In Appendix A is shown that this group of differential equations leads to a sixth order differential equation, which in fact, is the basis of the elastic theory of layered beams.

The most simplified method for the analysis of the CLT beam is the Bernoulli-Euler beam theory supposing the cross-section of the beam homogenous. The quantities MOR, MOE and FV defined by tests are used. A lot of full-scale bending tests have been completed to CLT beams, eg. Refs. [6], [7], [8], [49], [42], [11], [22]. In many of those studies the scope has been to define so called modulus of rupture (MOR) and the modulus of elasticity (MOE). MOR reflects the maximum load-carrying capacity of a member in bending and it describes the maximum axial stress of the top layer. In the referred test publications MOR is calculated using one, two or all three theories Gamma 
Method, Shear Analogy and Timoshenko Theory based on the measurements. MOE is the Young's modulus of the entire cross-section of the CLT beam. One, two or three theories are used frequently to calculate MOE based on the measured displacements. The difference is made between the global MOE and the local MOE. The global MOE is defined based on maximum deflection of the specimen and the local MOE is defined based on deflection at the shear force free area in four-point bending. In some tests the scope has been to define the shear resistance of the entire cross-section of the CLT beam, noted as FV. So, MOE, MOR and FV depend on the theory by which they are calculated based on experiments.

In most of the referred test studies the nominal sizes of specimens are used, dimensions were measured in Ref. [6]. The most important properties $E_{0}, E_{90}, G_{90}$ are not typically measured. One reference, Ref. [42] include the measurement of all these three values. One reference, Ref. [22], includes the measured values of $E_{0}$ and $E_{90}$ of the boards and one, Ref. [8], includes the measured value of $E_{0}$. In many tests are used visually graded wood and in the calculations are used the standard values of that wood grade. Deflections are given typically in graphs including the whole test data. In one reference, Ref. [22], are given the deflections in a numeric table. In some references the deflections are not given, but they are embedded in the MOE calculations. Two references include the use of strain gauges in the bending tests and in Ref. [7] the strains are given in a graph and in Ref. [42] the strains are embedded in the MOE calculations. The comparisons with the test results are possible using the given deflections, and in some cases with the measured strains.

The scope of this study is to use the well-known elastic theory of layered beams in the analysis of the CLT beams. The theory was developed originally in 1940's for nailed layered wooden beams and shear walls, but after that, it has been widely used for sandwich structures, Refs. [45], [13].

The research question of this paper is to study how well the theory of layered beams simulates the behaviour of the CLT beams. In what follows, the theory of layered beams is outlined briefly followed by numerical examples including comparison to experimental as well as numerical solutions.

\section{Theory of layered beams}

In the theory of layered beams, the underlaying assumptions are:

1. For faces, the Euler-Bernoulli bending theory can be used, meaning that shear deformations of the faces are neglected when deriving the equations.

2. The cores connect the faces, and the cores are assumed to be continuous and resist elastically only shear.

3. The cross-section and stiffnesses of the faces and the cores are constant along the beam axis.

4. The deflections of all the faces are the same along the beam axis.

5. Generalized Bernoulli's hypothesis is valid: The centroids of the faces remain on the line when the beam bends. This hypothesis was introduced to the theory in Ref. [40]. 
The last assumption is true for the cross-section with two faces and for the symmetric cross-section with three faces. The hypothesis is valid also in some other special cases. Thus, the theory is valid only approximatively for the beams with another cross-sections. The exact method where the Generalized Bernoulli's hypothesis is not fulfilled, leads to the of the group of differential equations and these solutions can be derived approximatively, Refs. [41], [26]. Based on the abovementioned five assumptions, the differential equations of layered beams were derived in Refs. [38], [9], [25], [20] and [40]. In Ref. [9], the focus was in shear-walls and in Ref. [25], the focus was in sandwich structures. Many similar theories have been presented dealing with e.g., steel-concrete composite beams.

The theory leads to the solutions of fourth or sixth order differential equations. In Refs. [45] and [13] are given many exact solutions for the equations with different boundary conditions and with different loading cases. An approximate finite element method for layered beams was derived in Ref. [46]. This FEM uses a cubic spline for the lateral deflection of the beam and trapezoidal splines for the axial displacements of the faces. This ensures that the FEM converges to the exact solution when the lengths of the finite elements are reduced. The exact finite element method formulations (the term "direct-stiffness method" is used in Ref. [12] instead of the term "exact FEM") for the layered beams are given in Ref. [24] and in Ref. [13]. The theory has been known over 70 years, so it can be called as the classical theory of layered beams.

Consider the general cross-section of the beam, which consists of $i(1, \ldots, n)$ faces and $j(1, \ldots, n-1)$ cores between the faces, see Figure 1 .

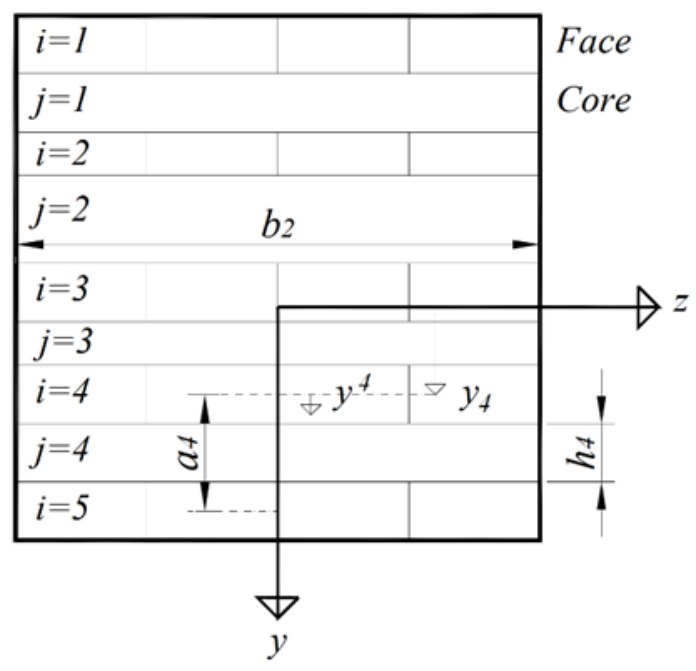

Figure 1. Cross-section of the layered beam, $n=5$.

If the beam is statically determined, i.e., the moment distribution $M(x)$ is known along the beam axis $x$ based on the equilibrium equations, then the governing fourth order differential equation of the deflection $v(x)$ is, Ref. [45] 


$$
\frac{d^{4} v(x)}{d x^{4}}-\frac{k B}{B_{0} B_{S}} \frac{d^{2} v(x)}{d x^{2}}=\frac{k}{B_{0} B_{S}} M(x)-\frac{1}{B_{0}} \frac{d^{2} M(x)}{d x^{2}},
$$

where $k$ is the shear factor of the layered beam, $B_{0}$ is the sum of bending stiffnesses of the faces $B_{i},(i=1, \ldots, n), B_{s}$ is the Steiner term of the faces with respect to the elastic centroid of the cross-section, and $B$ is the sum of $B_{0}$ and $B_{s}$.

More general sixth order differential equation is given in Ref. [24]:

$$
\frac{d^{6} v(x)}{d x^{6}}-\frac{B k}{B_{0} B_{s}} \frac{d^{4} v(x)}{d x^{4}}=\frac{1}{B_{0}} \frac{d^{2} p(x)}{d x^{2}}-\frac{k}{B_{0} B_{s}} p(x),
$$

where $p(x)$ is the loading intensity along the beam. The general equation is given in Ref. [24] including a distributed load, an axial force, an angular velocity, and a Winkler foundation.

It can be seen, that setting $B_{0}=0$ (thin faces) in Eq. (2) the result is of the same form as the differential equation for the well-known Timoshenko-beam. The exact FEM for the Timoshenko-beam has been presented in Ref. [12] and the dynamic case has been studied in Ref. [10]. The exact finite element discretization of Eq. (2) including the axial force and thermal loading is presented in Ref. [37]. The vibration case is considered in Refs. [33], [23]. The homogenous characteristic equation of Eq. (2) leads to the solution of the third order equation and its analytic solution is given in Ref. [24].

Different complementary boundary conditions can be given Refs. [13], [24] and in Ref. [24] are given for Eq. (2)

$$
\begin{aligned}
& Q_{y}=Q_{y}^{*} \text { or } v=v^{*}, \\
& M=M^{*} \text { or } \varphi=\varphi^{*}, \\
& M_{0}=M_{0}^{*} \text { or } \gamma=\gamma^{*},
\end{aligned}
$$

where $*$ means a known value. The angle $\gamma$ measures the slip between the centroids of the faces. The needed equations for the boundary conditions are

$$
\begin{aligned}
Q_{y} & =Q+N v^{\prime}, \\
Q=\sum_{i=1}^{n} Q_{i}+Q_{s} & =Q_{0}+Q_{s}=-B_{0} v^{\prime \prime \prime}+k \gamma, \\
M=\sum_{i=1}^{n} M_{i}+M_{s}=M_{0}+M_{s} & =-B_{0} v^{\prime \prime}-B_{s} v^{\prime \prime}+B_{s} \gamma^{\prime}=-B v^{\prime \prime}+B_{s} \gamma^{\prime}, \\
\varphi & =v^{\prime}-\gamma, \\
\gamma & =-\frac{B_{s}}{k}\left[\frac{B_{0} v^{(5)}}{k}+v^{\prime \prime \prime}+\frac{p^{\prime}}{k}\right],
\end{aligned}
$$

where $Q_{0}$ is the sum of the shear forces of the faces, $Q_{\mathrm{s}}$ is the shear force of the cores, $M_{0}$ is the sum of the bending moment of the faces, $M_{s}$ is the sum of the bending moments of axial forces of the faces.

In Ref. [40] is proposed, that the shear factor $k$ is calculated using the same shear stiffness intensities $k_{j}$ for all cores $j=1, \ldots, n-1$. In Ref. [39] is proposed, that the shear factor $k$ is calculated assuming the same elastic modulus for all faces $i=1, \ldots, n$. Here is used the following expression for the shear factor, Ref. [24]

$$
k=\sum_{j=1}^{n-1} a_{j}^{2} k_{j},
$$

where

$$
a_{j}=y_{i+1}-y_{i},
$$


and $y_{i}$ is the coordinate of the elastic centroid of the face $i$ and $k_{j}$ is the shear stiffness intensity of the core $j$, see Appendix B. If the core $j$ is made of periodical connectors with spacings $l_{s j}$ having a shear stiffness $k_{v j}$ of one connector, then $k_{j}=k_{v j} / l_{s j}$. The shear stiffness intensity of the layer $j$ of the CLT beam is

$$
k_{j}=\frac{G_{j} b_{j}}{h_{j}}=\frac{G_{90} b_{j}}{h_{j}},
$$

where $b_{j}$ is the width of the layer $j$ and $h_{j}$ is the height of the layer $j$.

The elastic centroid of the cross-section is defined as that point at which if $u^{\prime}=0(u$ being the axial displacement) then $N=0$. It follows that

$$
\sum_{i=1}^{n} y_{i} E_{i} A_{i}=0=>y_{i}=\sum_{m=1}^{i-1}\left(\frac{E_{m} A_{m}}{\sum_{i=1}^{n} E_{i} A_{i}} \sum_{j=m}^{i-1} a_{j}\right)-\sum_{m=i+1}^{n}\left(\frac{E_{m} A_{m}}{\sum_{i=1}^{n} E_{i} A_{i}} \sum_{j=i}^{m-1} a_{j}\right),
$$

where $E_{i}$ is the Young's modulus of the face $i$ and $A_{i}$ is the area of the face $i$. This formulation is used because here can be used the dimensions $a_{j}$ which are known without calculations of the coordinates at his stage. The bending stiffnesses are

$$
B_{i}=E_{i} I_{i}, B_{0}=\sum_{i=1}^{n} B_{i}=\sum_{i=1}^{n} E_{i} I_{i}, B_{s}=\sum_{i=1}^{n} y_{i}^{2} E_{i} A_{i},
$$

and $I_{i}$ is the second moment of the face $i$ with respect to $z_{i}$.

As an example, consider a simply supported beam of span $L$ with one concentrated load $F$ acting at $x=e$ and $\varepsilon=e / L$, see Figure 2. At the simply supported ends the sliding is free to occur between the faces. When the sliding is free to occur between the faces then the boundary condition is $M_{0}=0$. When the sliding is prevented then the boundary condition is $\gamma=0$, see the complementary conditions (5).

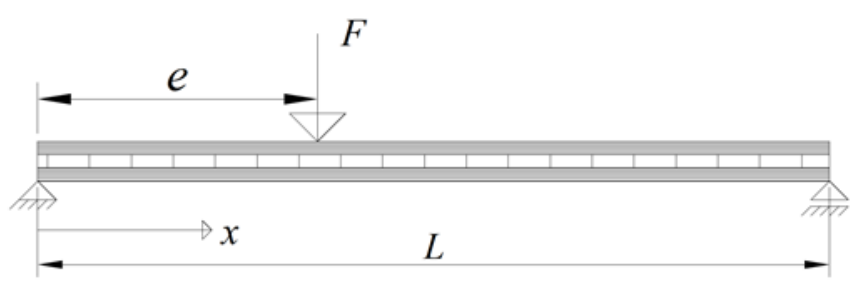

Figure 2. One span beam loaded with concentrated load.

The solution is given in Ref. [45] and it is using the notation $\xi=x / L$

$$
v_{1}(\xi)=\frac{F L^{3}}{B}\left[\frac{1}{6}(1-\varepsilon) \xi\left(2 \varepsilon-\varepsilon^{2}-\xi^{2}\right)+\frac{1}{\alpha \lambda^{2}}(1-\varepsilon) \xi-\frac{1}{\alpha \lambda^{3}} \frac{\sinh \lambda(1-\varepsilon)}{\sinh \lambda} \sinh \lambda \xi\right],
$$

and

$v_{2}(\xi)=\frac{F L^{3}}{B}\left[\frac{1}{6} \varepsilon(1-\xi)\left(-\varepsilon^{2}+2 \xi-\xi^{2}\right)+\frac{1}{\alpha \lambda^{2}} \varepsilon(1-\xi)-\frac{1}{\alpha \lambda^{3}} \frac{\sinh \lambda \varepsilon}{\sinh \lambda} \sinh \lambda(1-\xi)\right]$,

where index 1 is valid for $0 \leq \xi \leq \varepsilon$ and index 2 is valid for $\varepsilon \leq \xi \leq 1$. The bending moments and the shear forces are

$$
\begin{aligned}
& M_{s 1}=\frac{F L}{1+\alpha}\left[(1-\varepsilon) \xi-\frac{\sinh \lambda(1-\varepsilon)}{\lambda \sinh \lambda} \sinh \lambda \xi\right], \\
& M_{s 2}=\frac{F L}{1+\alpha}\left[\varepsilon(1-\xi)-\frac{\sinh \lambda \epsilon}{\lambda \sinh \lambda} \sinh \lambda(1-\xi)\right],
\end{aligned}
$$




$$
\begin{aligned}
M_{i 1} & =\frac{F L \alpha_{i}}{1+\alpha}\left[(1-\varepsilon) \xi+\frac{\sinh \lambda(1-\varepsilon)}{\alpha \lambda \sinh \lambda} \sinh \lambda \xi\right], i=1, \ldots, n, \\
M_{i 2} & =\frac{F L \alpha_{i}}{1+\alpha}\left[\varepsilon(1-\xi)+\frac{\sinh \lambda \varepsilon}{\alpha \lambda \sinh \lambda} \sinh \lambda(1-\xi)\right], i=1, \ldots, n, \\
Q_{s 1} & =\frac{F}{1+\alpha}\left[1-\varepsilon-\frac{\sinh \lambda(1-\varepsilon)}{\sinh \lambda} \cosh \lambda \xi\right], \\
Q_{s 2} & =\frac{F}{1+\alpha}\left[-\epsilon+\frac{\sinh \lambda \varepsilon}{\sinh \lambda} \cosh \lambda(1-\xi)\right], \\
Q_{i 1} & =\frac{F \alpha_{i}}{1+\alpha}\left[1-\epsilon+\frac{\sinh \lambda(1-\varepsilon)}{\alpha \sinh \lambda} \cosh \lambda \xi\right], i=1, \ldots, n, \\
Q_{i 2} & =\frac{F \alpha_{i}}{1+\alpha}\left[-\epsilon-\frac{\sinh \lambda \varepsilon}{\alpha \sinh \lambda} \cosh \lambda(1-\xi)\right], i=1, \ldots, n,
\end{aligned}
$$

where index 1 is valid for $0 \leq \xi \leq \varepsilon$ and index 2 is valid for $\varepsilon \leq \xi \leq 1$. Here are used the notations

$$
\alpha_{i}=\frac{B_{i}}{B_{s}}, \alpha=\sum_{i=1}^{n} \alpha_{i}=\frac{B_{0}}{B_{s}}, \beta=\frac{B_{s}}{k L^{2}} \text { and } \lambda^{2}=\frac{1+\alpha}{\alpha \beta},
$$

The shear stress $\tau_{j}$ of the core $j$ is

$$
\tau_{j}=\frac{T_{j}}{b_{j}}=\frac{k_{j} a_{j}}{b_{j}} \gamma, j=1, \ldots, n-1,
$$

where $T_{j}=k_{j} a_{j} \gamma=k_{j} a_{j} Q_{s} / k$ is the shear flow on the core $j$. The maximum value of the component $\tau_{i}$ of the shear stress of the face $i$ is, assuming the parabolic shear stress distribution over the face

$$
\tau_{i}=\frac{1.5 Q_{i}}{A_{i}}, i=1, \ldots, n
$$

The axial stress of the face $i$ is

$$
\sigma_{i}=\frac{E_{i}}{\sum_{i=1}^{n} E_{i} A_{i}} N+\frac{E_{i} y^{i}}{B_{0}} M_{0}+\frac{y_{i} E_{i}}{B_{s}} M_{s}, i=1, \ldots, n,
$$

where $y^{i}$ is the local coordinate of the face $i$, see Figure 1 .

\section{3-, 5- and 7-layer beams}

In Ref. [22] are given test results of 3-layer and 5-layer CLT beams, which are fabricated using Nr.2-grade Canadian black spruce lumber. Long beams (bending tests) are tested with four-point bending and short beams (shear tests) with three-point bending. Totally ten $3.3 \mathrm{~m}$ long 3-layer beams and ten $4.8 \mathrm{~m}$ long 5-layer beams were tested. Totally ten $0.68 \mathrm{~m}$ long 3-layer beams and ten $1.0 \mathrm{~m}$ long 5-layer beams were tested in the shear tests.

The widths of all beams were $310 \mathrm{~mm}$. The measured Young's moduli of the boards were $E_{0}=10925 \mathrm{MPa}$ in parallel to grain and $E_{90}=993 \mathrm{MPa}$ in perpendicular to grain directions, and the compression strengths were $28.7 \mathrm{MPa}$ and $5.8 \mathrm{MPa}$, respectively. The average densities were $490 \mathrm{~kg} / \mathrm{m}^{3}$ for 3-layer panels and $486 \mathrm{~kg} / \mathrm{m}^{3}$ for 5 -layer panels. The 3-layer panel was made of three $35 \mathrm{~mm}$ thick layers, the total height being $105 \mathrm{~mm}$. The 5-layer panel was made of 35, 25, 35, 25 and $35 \mathrm{~mm}$ thick layers, the total height being $155 \mathrm{~mm}$. The loading and support conditions for the long and short beams are shown in Figure 3. 
a)

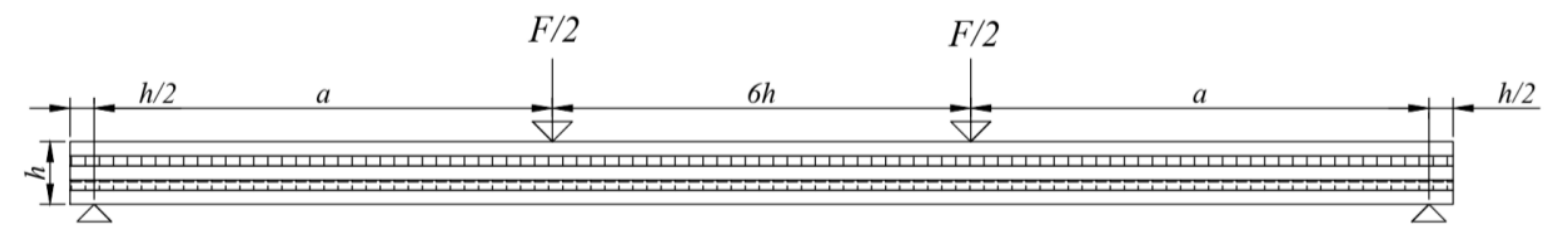

b)

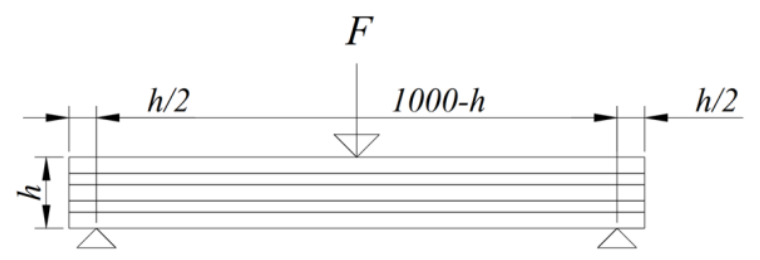

Figure 3. Loading and support conditions in the tests for 5-layer beams, Ref. [22], a) long beams, b) short beams.

The shear stiffness intensity $k_{j}$ and the shear factor $k$ are calculated for the transverse direction (layer where the grain direction is perpendicular to the beam axis) using the equations (11) - (13). Using the approximation of Ref. [18] the shear moduli are $G_{0}=$ $10925 / 16=683 \mathrm{MPa}$ and $G_{90}=683 / 10=68.3 \mathrm{MPa}$. All the CLT panels considered in Ref. [22] were edge glued. If the Young's moduli $E_{90}$ in the perpendicular directions are set to zero, then the 3-layer beam can be considered as a layered beam with two faces and the 5-layer beam as a symmetric layered beam with three faces. These crosssections are such, that the centroids of the faces remain at the line in bending, and the Generalized Bernoulli's hypothesis is automatically fulfilled. The theory of layered beams can be used for the considered cases using the theory with three faces to the 3layer beams and with five faces to the 5-layer beams. This means that the Young's moduli in the transverse directions are considered when calculating the bending stiffness. The shear factor is calculated only for the transverse directions also in this case. By these means the basic assumption number 2 of the theory is violated and the theory is applied only approximatively. The quantities needed in the analysis using the theory of layered beams are given in Table 1. The load level is chosen so, that the beams are at the elastic phase.

The deflection $v$ and the stress resultants $M$ and $Q$ of the long 3-layer beam can be calculated by summing the effects of two concentrated loads from the equations (16) (25) by setting $\varepsilon=0.4014$ and 0.5986 . The deflections and the moments and the shear forces are given in Figures 4-6. The Young's modulus is $E_{90}=0 \mathrm{MPa}$ for the transverse direction. 
Table 1. Input for analysis of layered beams. The value $E_{90}=0 \mathrm{MPa}$ indicates that the Young's modulus of transverse layers are not considered and the value $E_{90}=993 \mathrm{MPa}$ indicates that they are considered.

\begin{tabular}{|c|c|c|c|c|c|c|c|c|}
\hline Property & \multicolumn{2}{|c|}{ Long 3-layer beam } & \multicolumn{2}{|c|}{ Long 5-layer beam } & \multicolumn{2}{|c|}{ Short 3-layer beam } & \multicolumn{2}{|c|}{ Short 5-layer beam } \\
\hline $\begin{array}{l}\text { Span } \\
\text { (mm) }\end{array}$ & \multicolumn{2}{|c|}{3195} & \multicolumn{2}{|c|}{4645} & \multicolumn{2}{|c|}{575} & \multicolumn{2}{|c|}{845} \\
\hline $\begin{array}{l}\text { Distance } \\
\text { of load } \\
\text { from } \\
\text { support } \\
\text { (mm) }\end{array}$ & \multicolumn{2}{|c|}{1282.5} & \multicolumn{2}{|c|}{1857.5} & \multicolumn{2}{|c|}{287.5} & \multicolumn{2}{|c|}{422.5} \\
\hline $\begin{array}{l}\text { Total } \\
\text { load } \\
(\mathrm{kN})\end{array}$ & \multicolumn{2}{|c|}{13.49} & \multicolumn{2}{|c|}{14.8} & \multicolumn{2}{|c|}{30} & \multicolumn{2}{|c|}{60} \\
\hline $\begin{array}{l}E_{90} \\
(\mathrm{MPa})\end{array}$ & 0 & 993 & 0 & 993 & 0 & 993 & 0 & 993 \\
\hline $\begin{array}{l}B_{i} \\
\left(\mathrm{Nmm}^{2}\right)\end{array}$ & $1.210 \mathrm{E}+10$ & $1.210 \mathrm{E}+10$ & $1.210 \mathrm{E}+10$ & $1.210 \mathrm{E}+10$ & $1.210 \mathrm{E}+10$ & $1.210 \mathrm{E}+10$ & $1.210 \mathrm{E}+10$ & $1.210 \mathrm{E}+10$ \\
\hline $\begin{array}{l}B_{0} \\
\left(\mathrm{Nmm}^{2}\right)\end{array}$ & $2.420 \mathrm{E}+10$ & $2.530 \mathrm{E}+10$ & $3.630 \mathrm{E}+10$ & $3.710 \mathrm{E}+10$ & $2.420 \mathrm{E}+10$ & $2.530 \mathrm{E}+10$ & $3.630 \mathrm{E}+10$ & $3.710 \mathrm{E}+10$ \\
\hline $\begin{array}{l}B_{s} \\
\left(\mathrm{Nmm}^{2}\right)\end{array}$ & $2.904 \mathrm{E}+11$ & $2.904 \mathrm{E}+11$ & $8.535 \mathrm{E}+11$ & $8.673 \mathrm{E}+11$ & $2.904 \mathrm{E}+11$ & $2.904 \mathrm{E}+11$ & $8.535 \mathrm{E}+11$ & $8.673 \mathrm{E}+11$ \\
\hline $\begin{array}{l}B \\
\left(\mathrm{Nmm}^{2}\right)\end{array}$ & $3.146 \mathrm{E}+11$ & $3.157 \mathrm{E}+11$ & $8.898 \mathrm{E}+11$ & $9.044 \mathrm{E}+11$ & $3.146 \mathrm{E}+11$ & $3.157 \mathrm{E}+11$ & $8.898 \mathrm{E}+11$ & $9.044 \mathrm{E}+11$ \\
\hline $\begin{array}{l}k_{j} \\
\left(\mathrm{~N} / \mathrm{mm}^{2}\right)\end{array}$ & 605 & 605 & 846 & 847 & 605 & 605 & 846 & 847 \\
\hline$k(\mathrm{~N})$ & 2963406 & 2963406 & 6096150 & 6096150 & 2963406 & 2963406 & 6096150 & 6096150 \\
\hline$\alpha$ & 0.083 & 0.087 & 0.043 & 0.043 & 0.083 & 0.087 & 0.043 & 0.043 \\
\hline$\beta$ & 0.010 & 0.010 & 0.006 & 0.007 & 0.296 & 0.296 & 0.196 & 0.199 \\
\hline$\lambda$ & 36.798 & 36.053 & 61.460 & 60.800 & 6.623 & 6.488 & 11.181 & 11.060 \\
\hline
\end{tabular}

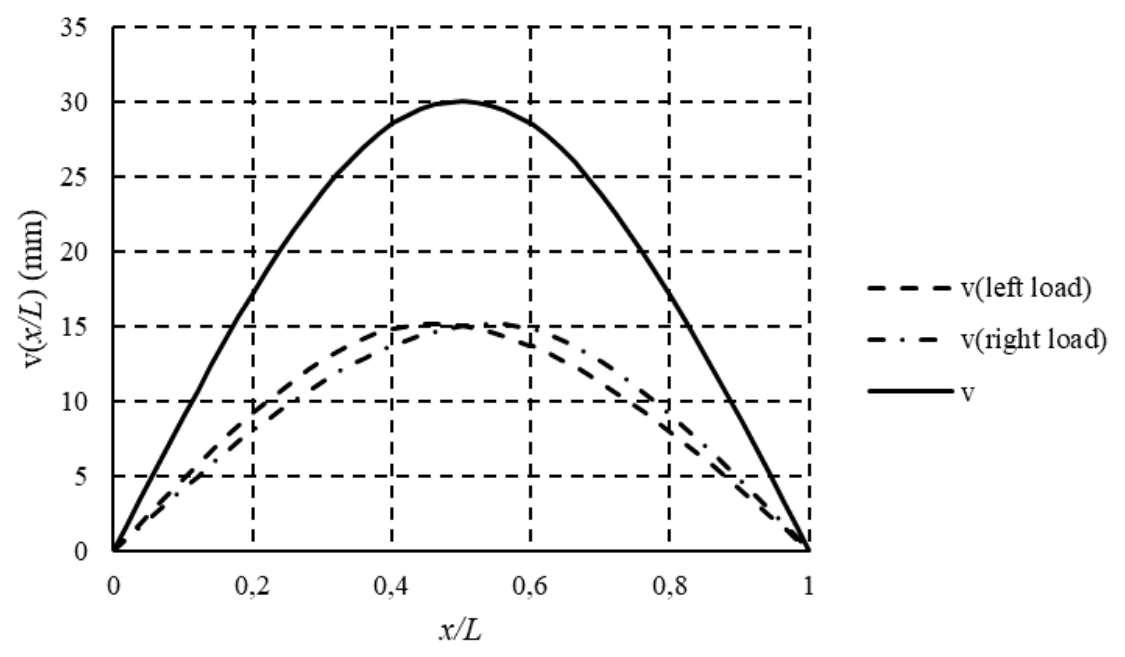

Figure 4. Deflections of long 3-layer beam. 


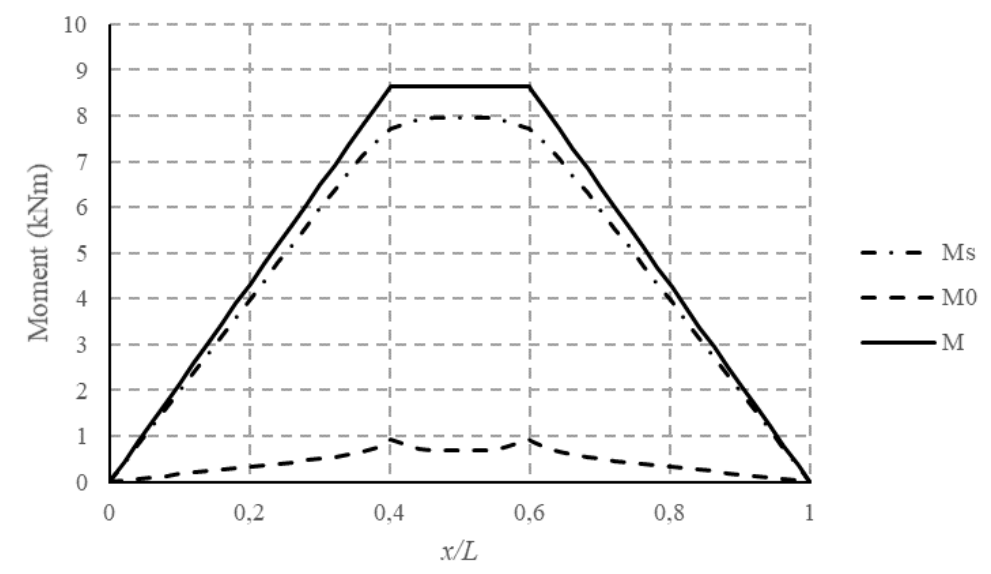

Figure 5. Bending moments with total load $13.48 \mathrm{kN}$ of long 3-layer beam.

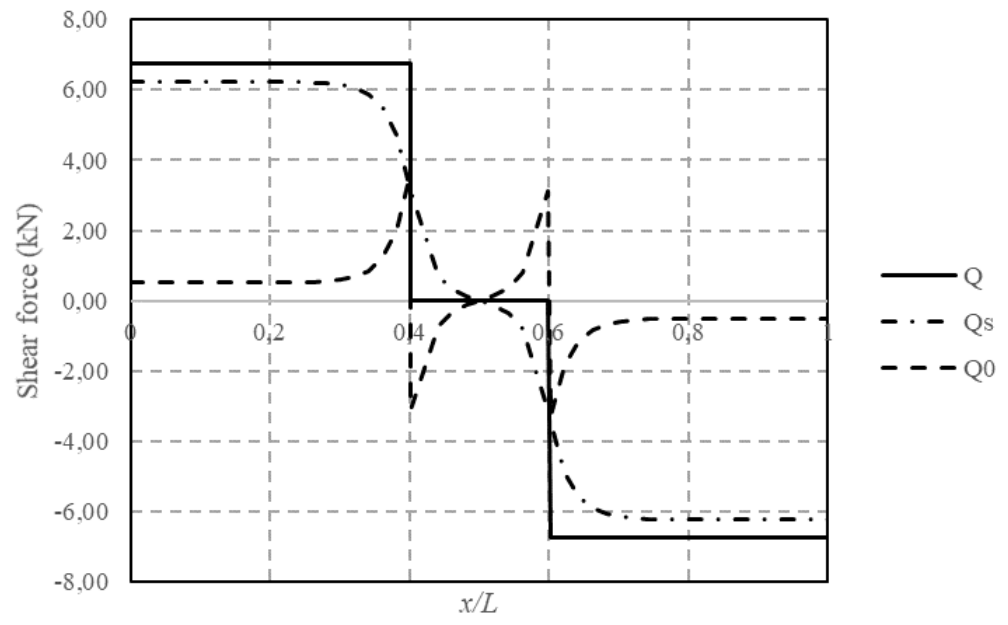

Figure 6. Shear forces with total load $13.48 \mathrm{kN}$ of long 3-layer beam.

In Figure 5, it can be seen that the moment $M_{s}$ carries the larger part of the total moment $M$ than the moment $M_{0}$. In Figure 6 , it can be seen that the shear force $Q_{0}$ (faces) decreases when approaching the supports, and this can be seen in the shear stresses of the faces. Figures 7-9 show the shear stresses, Eq. (28), the axial stresses, Eq. (29), and the axial strains $\varepsilon=\sigma / E$ of the 3-layer beam.

The shear stresses of the top and bottom layers are the major parts of the total stresses at the loading point because these layers carry mainly the concentrated loads. These stresses are decreasing when approaching the supports, and this can be seen in the shear force $Q_{0}$ distribution in Figure 6. In Ref. [35] has been shown similar results using the Shear Analogy and the results are compared to the results of the FE-model. However, the used FE-model did not give such major parts of the shear stresses near the loading point, because the concentrated load in the FE-model was distributed to the entire cross-section of the beam. 


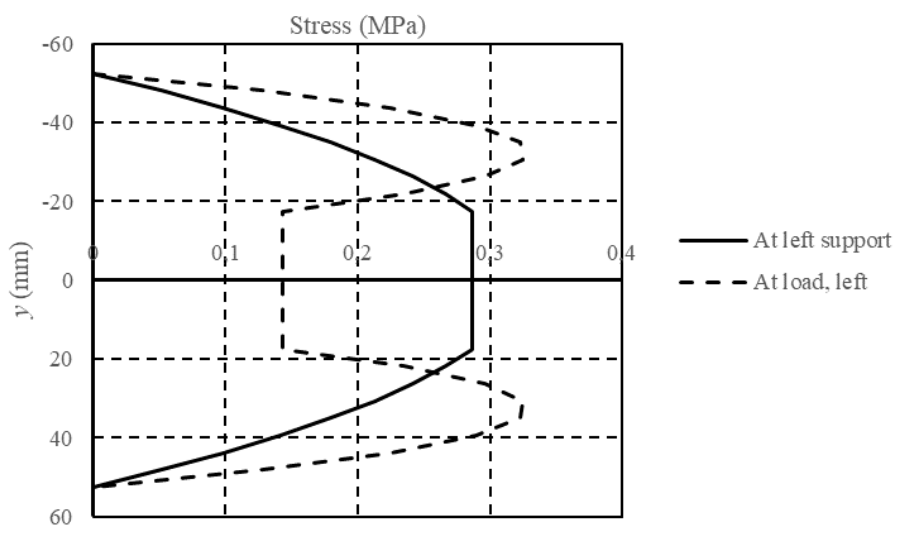

Figure 7. Shear stresses of long 3-layer beam, $E_{90}=0 \mathrm{MPa}$.

The axial stresses and strains are calculated both using $E_{90}=0 \mathrm{MPa}$ (With 2 faces) and $E_{90}=993 \mathrm{MPa}$ (With 3 faces). The axial stresses are a little bit larger at the loading point, than at the mid-point of the beam.

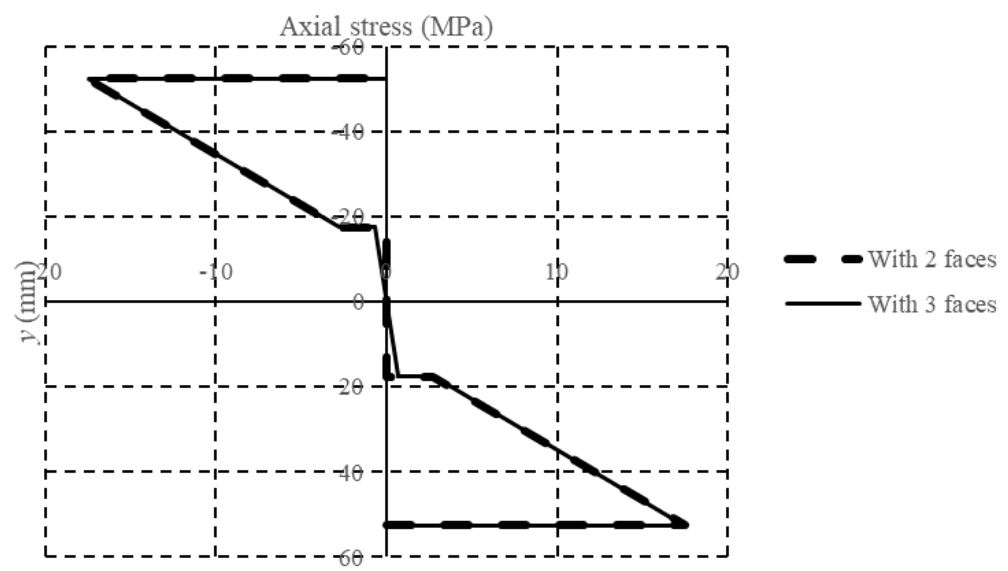

Figure 8. Axial stresses at load point of long 3-layer beam.

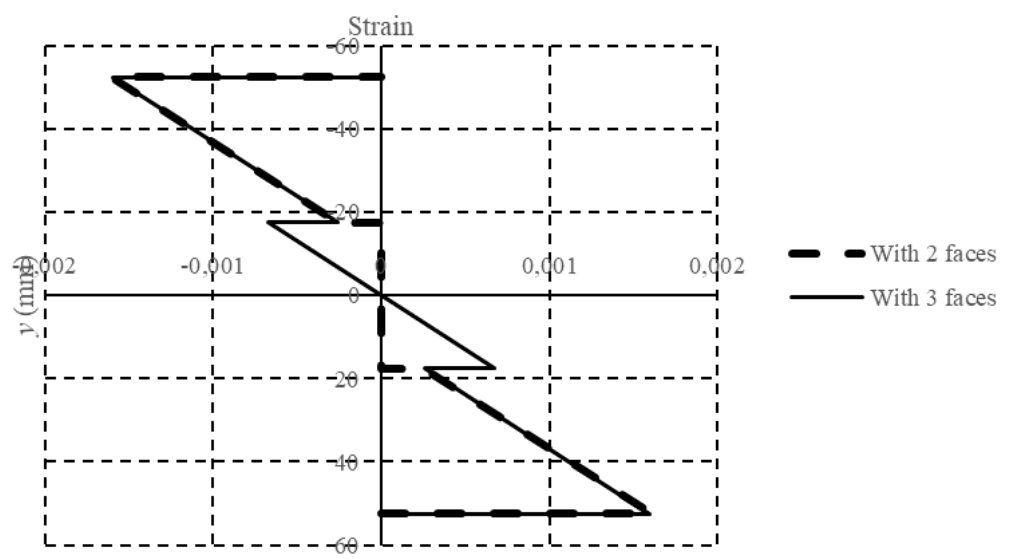

Figure 9. Axial strains at load point of long 3-layer beam. 
It is seen in Figures 8 and 9 that the differences of the axial stresses and strains are not large at the outmost layers between "With 2 faces" and "With 3 faces". Using the theory "With 3 faces" the tensile stress in the transverse direction, which may be critical in many cases, can be simulated. It is seen in Figure 9 that the Bernoulli's hypothesis is not fulfilled, as was found in Ref. [35], too. However, the generalized Bernoulli's hypothesis is valid, as is assumed in the theory of layered beams.

Similar distributions were found for the deflections and for the stress resultants of the long 5-layer beam. The stresses and the strains of the long 5-layer beam are given in Figures 10-12. Figures 13 and 14 show the moments and the shear forces of the short 5layer beam.

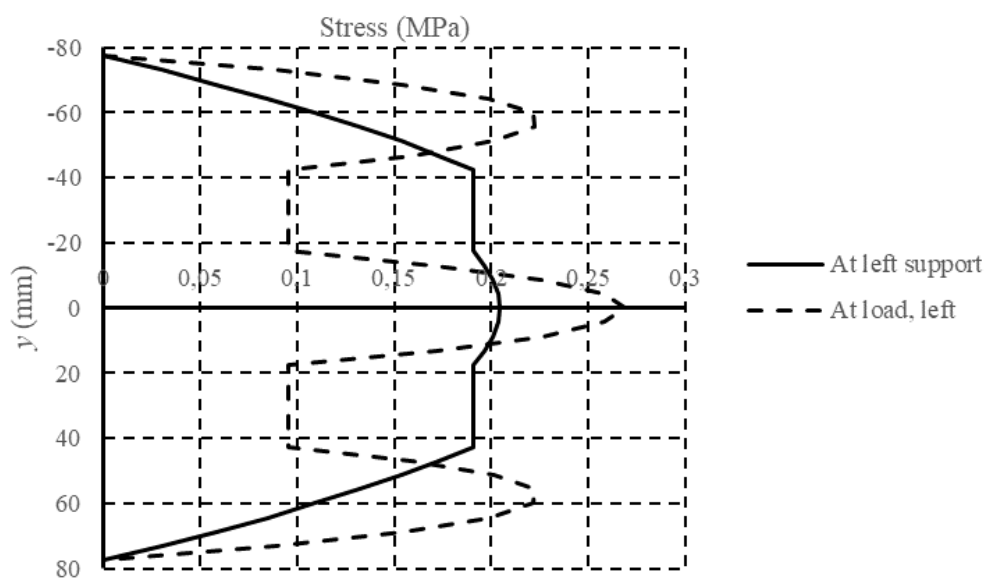

Figure 10. Shear stresses of long 5-layer beam.

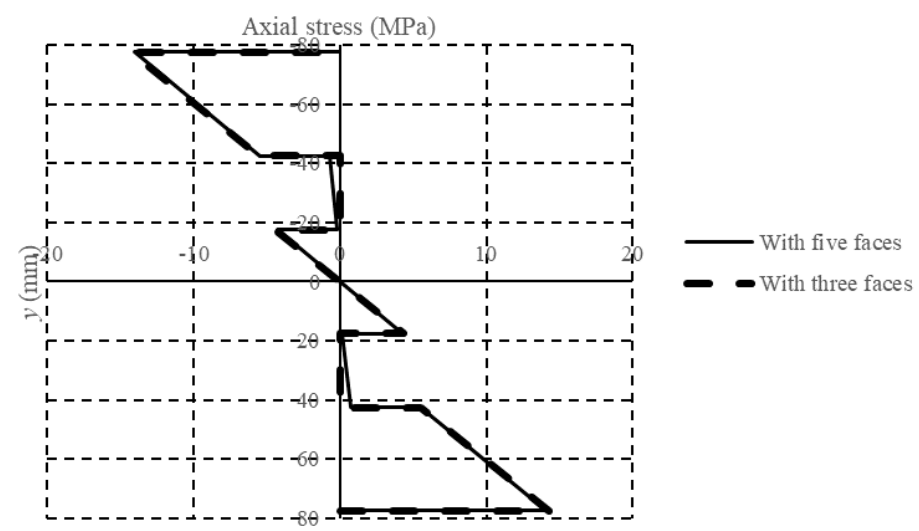

Figure 11. Axial stresses at load point of long 5-layer beam. 


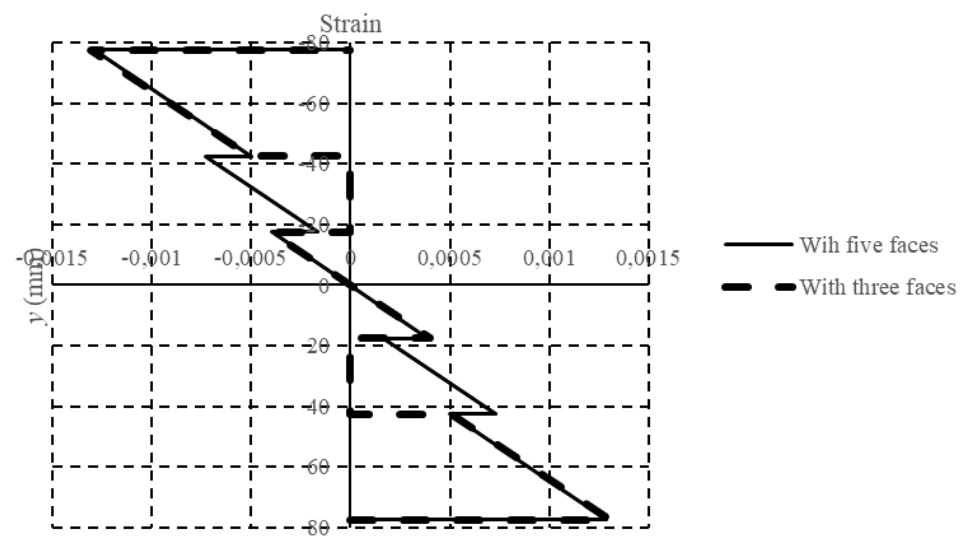

Figure 12. Axial strains at load point of long 5-layer beam.

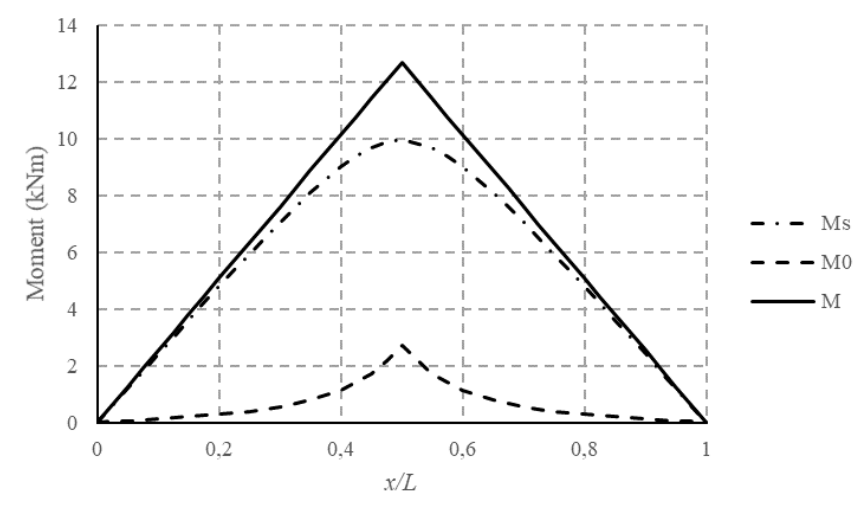

Figure 13. Bending moments with total load $60 \mathrm{kN}$ of short 5-layer beam.

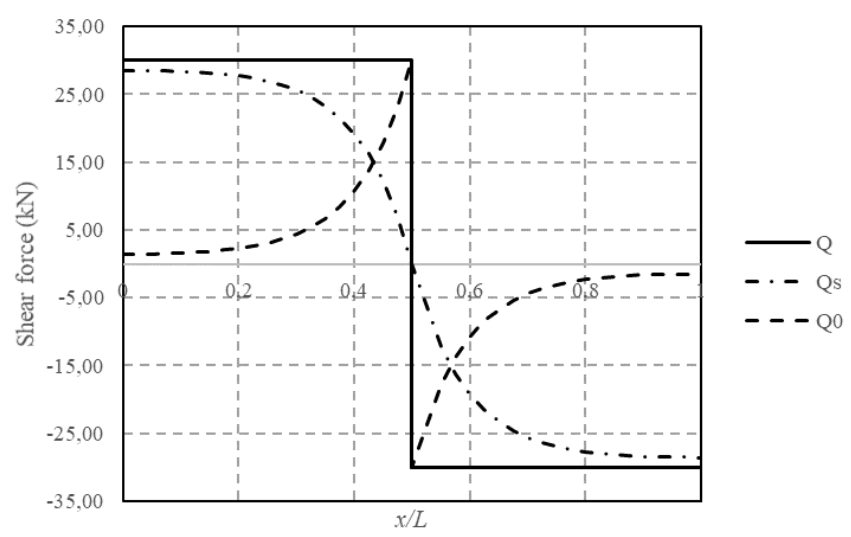

Figure 14. Shear forces with total load $60 \mathrm{kN}$ of short 5-layer beam. 


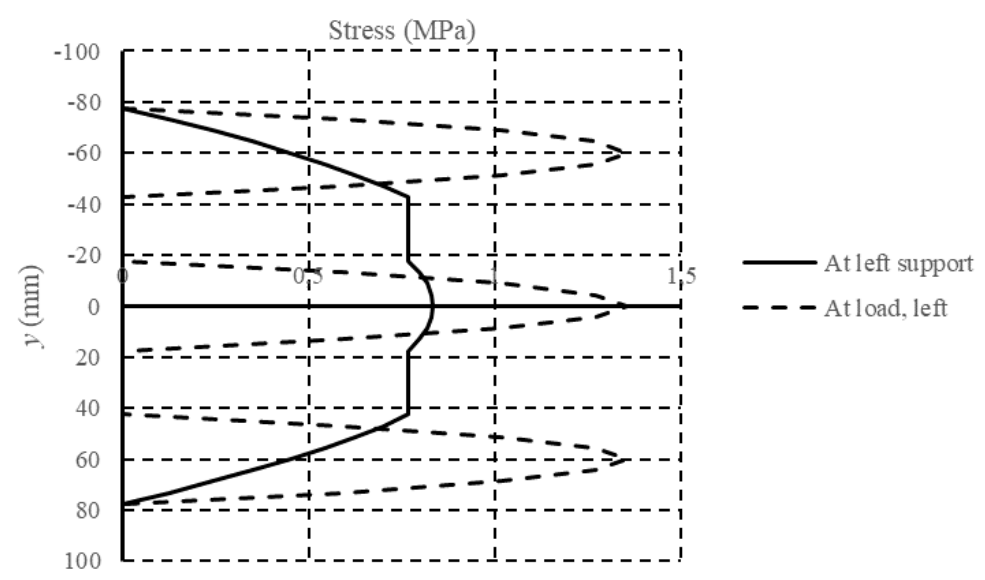

Figure 15. Shear stresses of short 5-layer beam.

Similar distributions were got for the short 3-layer beam. The shear stresses, axial stresses and axial strains for the short 5-layer beam are shown in Figures 15-17. In this case, the shear stresses vanish at the loading point in the layers 2 and 4 , because the shear force $Q_{s}$ is zero at this point, see Figure 14. The shear force $Q_{s}=0$ due to symmetry and the shear angle $\gamma=0$ at the mid-point of the beam.

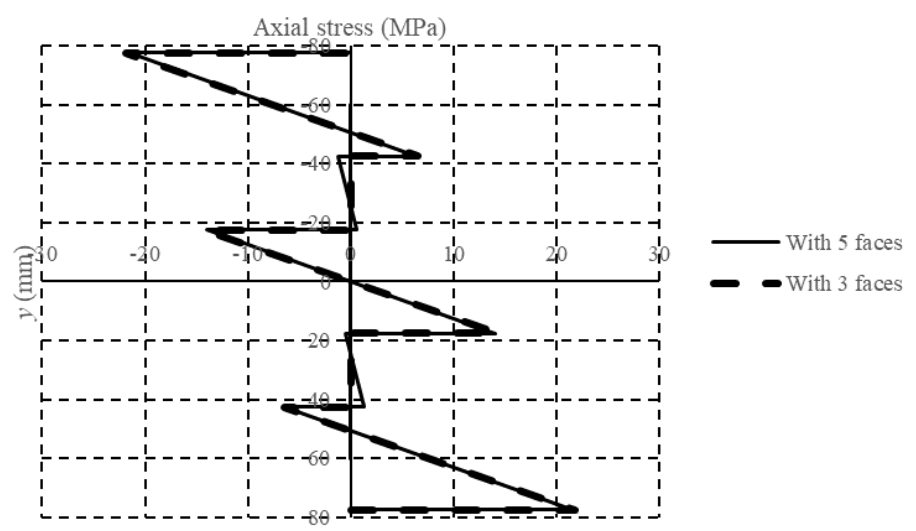

Figure 16. Axial stresses at mid-point of short 5-layer beam.

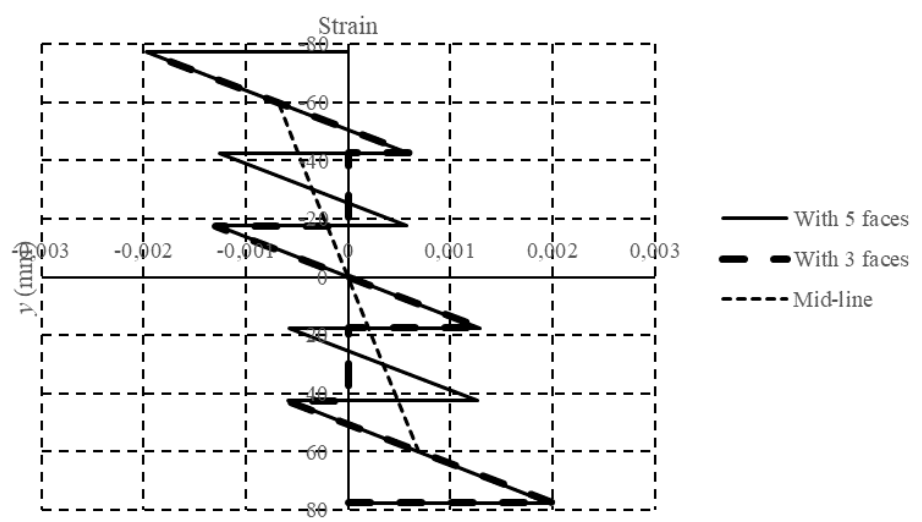

Figure 17. Axial strains at mid-point of short 5-layer beam. 
The deflections and the maximum loads in the tests are given in Table 2. The given values of the tests are the mean values of ten tests. In Table 2 are given the deflections using the Timoshenko theory for comparisons.

Table 2. Deflections and maximum loads of the cases Ref. [22].

\begin{tabular}{|l|c|c|c|c|}
\hline & $\begin{array}{c}\text { Long 3- } \\
\text { layer beam }\end{array}$ & $\begin{array}{c}\text { Long 5- } \\
\text { layer beam }\end{array}$ & $\begin{array}{c}\text { Short 3- } \\
\text { layer beam }\end{array}$ & $\begin{array}{c}\text { Short 5- } \\
\text { layer beam }\end{array}$ \\
\hline Load $(\mathrm{kN})$ & 13.49 & 14.8 & $30^{1}$ & 60 \\
\hline Deflection in tests $(\mathrm{mm})$ & 26.7 & 34.6 & $1.2^{1,2}$ & $2.2^{2}$ \\
\hline Deflection, present theory $(\mathrm{mm}), E_{90}=0 \mathrm{MPa}$ & 30.0 & 34.9 & 1.2 & 2.4 \\
\hline Deflection $(\mathrm{mm}), E_{90}=993 \mathrm{MPa}$ & 29.9 & 34.3 & 1.2 & 2.4 \\
\hline Deflection $(\mathrm{mm})$, Timoshenko theory & 27.8 & 32.6 & 1.8 & 3.6 \\
\hline
\end{tabular}

${ }^{1}$ Nine tests, ${ }^{2}$ Measured from the figure.

It is seen that the theory of layered beams gives about same deflections to the short beams and to the long 5-layer beams than the tests, but not so good results to the long 3layer beam. The deflection using the theory of layered beams is larger than the measured deflection in this case.

In Table 3 are compared the results of the theory of layered beams to test results. The test results are the means of 3-10 measurements. The load level is chosen to the elastic phase. All cases are calculated by considering the bending stiffnesses in the transverse directions.

It is seen that the axial strains of the bottom layers can be simulated well using the theory of layered beams compared to the tests, although there were found only five samples to the comparisons. The ratios of the calculated maximum deflections to the observed test values are in the mean 1.10 in 18 cases. The minimum ratio is 0.98 and the maximum ratio is 1.29 . When considering the design, the deflection based on the theory of layered beams is on the safe side in almost all 18 cases.

\section{Unsymmetric beam}

Comparisons of the results of the layered beam theory are done with the results of the FE-models using program Autodesk Robot Structural Analysis Professional, Version 33.0.6930 (x64). The reason for using finite element model for comparison is due to the fact, that the layered beam theory assumes Bernoulli hypothesis to hold for the parallel layers and parabolic distribution for the shear and the Generalized Bernoulli hypothesis to the entire cross-section. Square four node plane stress elements with an orthotropic material are used. Consider an unsymmetric cross-section, Figure 18, similar as is shown in Ref. [4]. This case introduces the structure, where the Generalized Bernoulli's hypothesis is not presumably valid. The cross-section is composed of five faces (the elastic modules in the transverse direction are taken into account) and the shear factor is defined considering two layers in the transverse direction, see Figure 18. The face is the layer which bending stiffness is taken into account in the analysis using the theory of the layered beam. The core is the layer which shear deformation is considered, see also the basic assumptions 1 and 2 . 
Table 3. Comparisons with test results.

\begin{tabular}{|c|c|c|c|c|c|c|}
\hline Reference, case & $\begin{array}{c}\text { Origin of modulus } \\
E_{0} \text { and } E_{90}\end{array}$ & $\begin{array}{l}\text { Total } \\
\text { load } \\
(\mathrm{kN})\end{array}$ & $\begin{array}{l}\text { Measured } \\
\text { deflection } \\
(\mathrm{mm})\end{array}$ & $\begin{array}{l}\text { Calculated } \\
\text { deflection } \\
(\mathrm{mm})\end{array}$ & $\begin{array}{l}\text { Measured } \\
\text { axial strain } \\
\text { of bottom } \\
\text { layer }\end{array}$ & $\begin{array}{l}\text { Calculated } \\
\text { axial strain } \\
\text { of bottom } \\
\text { layer }\end{array}$ \\
\hline $\begin{array}{l}\text { [7], 3-layers, span } 1.8 \mathrm{~m} \text {, } \\
\text { four point bending }\end{array}$ & [4] & 5 & 7 & 8.7 & 0.0068 & 0.0067 \\
\hline $\begin{array}{l}\text { [7], 3-layers, span } 1.8 \mathrm{~m} \text {, } \\
\text { three point bending }\end{array}$ & [4] & 15 & 29 & 31.1 & 0.0028 & 0.0037 \\
\hline $\begin{array}{l}\text { [6], } 5 \text {-layers, span } 1.71 \mathrm{~m} \text {, } \\
\text { four point bending }\end{array}$ & [4] & 60 & 16 & 18 & & \\
\hline $\begin{array}{l}{[8], 3 \text {-layers }(20 \mathrm{~mm}) \text {, span }} \\
1.44 \mathrm{~m} \text {, four point bending }\end{array}$ & $\begin{array}{c}E_{0} \text { measured, } \\
\text { others [4], C16 }\end{array}$ & 20 & 14.5 & 15.8 & & \\
\hline $\begin{array}{l}\text { [8], 5-layers }(20 \mathrm{~mm}), \text { span } \\
2.40 \mathrm{~m} \text {, four point bending }\end{array}$ & $\begin{array}{c}E_{0} \text { measured, } \\
\text { others [4], C16 }\end{array}$ & 20 & 16.7 & 18.5 & & \\
\hline $\begin{array}{l}\text { [8], 3-layers }(40 \mathrm{~mm}), \text { span } \\
2.88 \mathrm{~m} \text {, four point bending }\end{array}$ & $\begin{array}{c}E_{0} \text { measured, } \\
\text { others [4], C16 }\end{array}$ & 20 & 14.6 & 15.8 & & \\
\hline $\begin{array}{l}\text { [8], 3-layers }(20 \mathrm{~mm}) \text {, span } \\
0.72 \mathrm{~m} \text {, four point bending }\end{array}$ & $\begin{array}{c}E_{0} \text { measured, } \\
\text { others [4], C16 }\end{array}$ & 40 & - & 3.9 & & \\
\hline $\begin{array}{l}{[8], 5 \text {-layers }(20 \mathrm{~mm}) \text {, span }} \\
1.20 \mathrm{~m} \text {, four point bending }\end{array}$ & $\begin{array}{c}E_{0} \text { measured, } \\
\text { others [4], C16 }\end{array}$ & 40 & - & 2.2 & & \\
\hline $\begin{array}{l}\text { [8], 3-layers }(40 \mathrm{~mm}) \text {, span } \\
1.44 \mathrm{~m} \text {, four point bending }\end{array}$ & $\begin{array}{c}E_{0} \text { measured, } \\
\text { others [4], C16 }\end{array}$ & 40 & 4 & 3.9 & & \\
\hline $\begin{array}{l}\text { [42], 3-layers, span } 1.26 \mathrm{~m} \text {, } \\
\text { four point bending }\end{array}$ & $\begin{array}{l}\text { Measured also } \\
G_{90}\end{array}$ & 20 & 3 & 3.1 & 0.00061 & 0.00057 \\
\hline $\begin{array}{l}\text { [42], 3-layers, span } 1.89 \mathrm{~m} \text {, } \\
\text { four point bending }\end{array}$ & $\begin{array}{l}\text { Measured also } \\
G_{90}\end{array}$ & 20 & 8 & 10.3 & 0.00106 & 0.00112 \\
\hline $\begin{array}{l}\text { [42], 3-layers, span } 2.52 \mathrm{~m} \text {, } \\
\text { four point bending }\end{array}$ & $\begin{array}{c}\text { Measured also } \\
G_{90}\end{array}$ & 20 & 21 & 23.8 & 0.00161 & 0.00167 \\
\hline $\begin{array}{l}\text { [11], 3-layers }(19 \mathrm{~mm}) \text {, span } \\
1.026 \mathrm{~m} \text {, four point bending }\end{array}$ & [4] & 20 & 9.6 & 9.7 & & \\
\hline $\begin{array}{l}\text { [11], 3-layers }(19 \mathrm{~mm}) \text {, span } \\
0.513 \mathrm{~m} \text {, four point bending }\end{array}$ & [4] & 20 & - & 1.9 & & \\
\hline $\begin{array}{l}\text { [11], 3-layers }(44 \mathrm{~mm}) \text {, span } \\
2.34 \mathrm{~m} \text {, four point bending }\end{array}$ & [4] & 20 & 10.4 & 11.1 & & \\
\hline $\begin{array}{l}\text { [11], 3-layers }(44 \mathrm{~mm}), \text { span } \\
1.188 \mathrm{~m} \text {, four point bending }\end{array}$ & [4] & 20 & - & 2.2 & & \\
\hline $\begin{array}{l}\text { [11], 7-layers, span } 5.4 \mathrm{~m} \text {, } \\
\text { four point bending }\end{array}$ & [4] & 20 & 9.9 & 11.0 & & \\
\hline $\begin{array}{l}\text { [11], 7-layers, span } 2.7 \mathrm{~m} \text {, } \\
\text { four point bending }\end{array}$ & [4] & 20 & - & 2.4 & & \\
\hline $\begin{array}{l}\text { [49], 5-layers, span } 3.15 \mathrm{~m} \text {, } \\
\text { four point bending }\end{array}$ & $\begin{array}{c}\text { US standard } E_{0} \\
=1800000 \mathrm{psi}, \\
E_{90}[4]\end{array}$ & 20 & 9.0 & 9.7 & & \\
\hline $\begin{array}{l}\text { [49], 5-layers, span } 3.15 \mathrm{~m} \text {, } \\
\text { four point bending, rotated } \\
90^{\circ} \text { from pervious }\end{array}$ & $\begin{array}{l}\text { US standard } E_{0} \\
=1400000 \mathrm{psi} \\
E_{90}[4]\end{array}$ & 10 & 16.6 & 19.5 & & \\
\hline
\end{tabular}




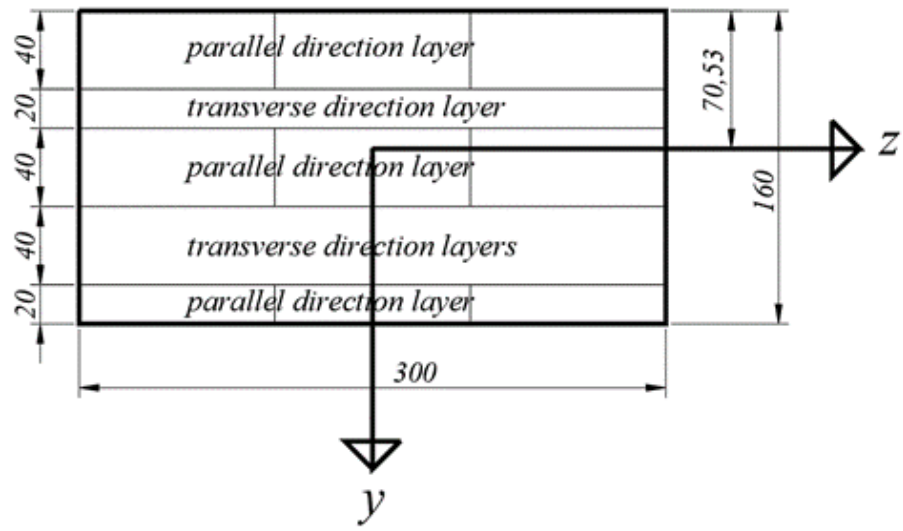

Figure 18. Unsymmetric cross-section of the beam, dimensions in mms.

The dimensions of the cross-section are shown in Figure 18, including the location of the elastic centroid. The elastic properties of the grade C24 are as they are given in Ref. [4]: parallel direction $E_{0}=11000 \mathrm{MPa}$, transverse direction $E_{90}=370 \mathrm{MPa}$ and $G_{90}$ $=50 \mathrm{MPa}$ (rolling shear). A simply supported beam of the span $3 \mathrm{~m}$ is considered with a concentrated load $15 \mathrm{kN}$ located at $1 \mathrm{~m}$ from the left support. The moments and the shear forces using the theory of layered beams are shown in Figures 19 and 20.

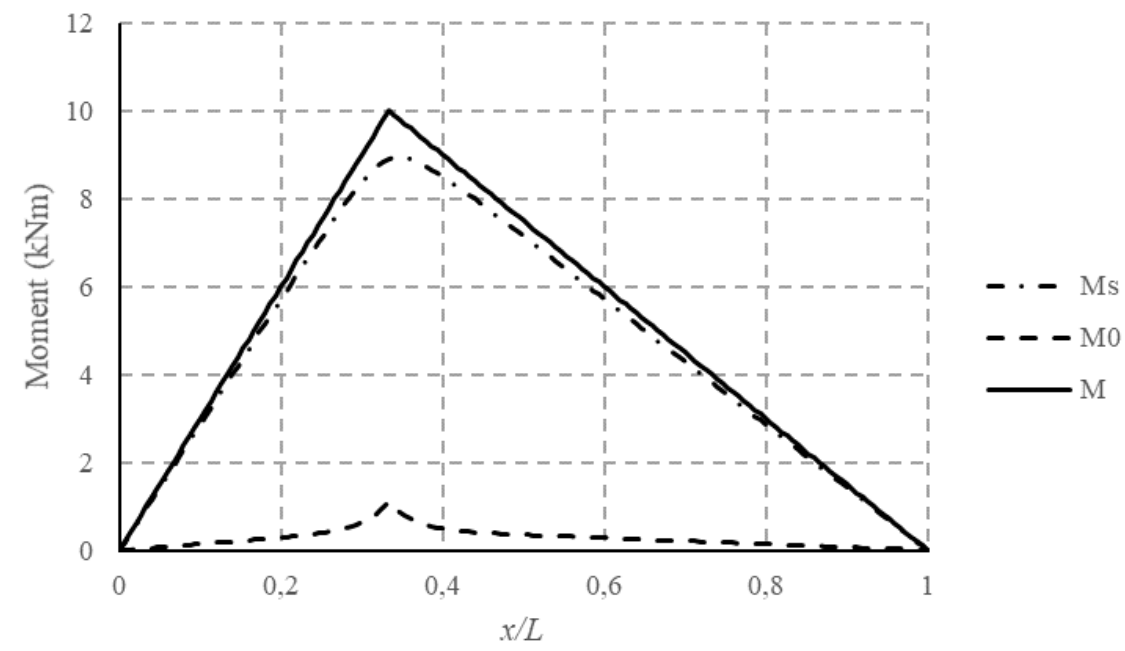

Figure 19. Moments with load $15 \mathrm{kN}$ of unsymmetric beam. 


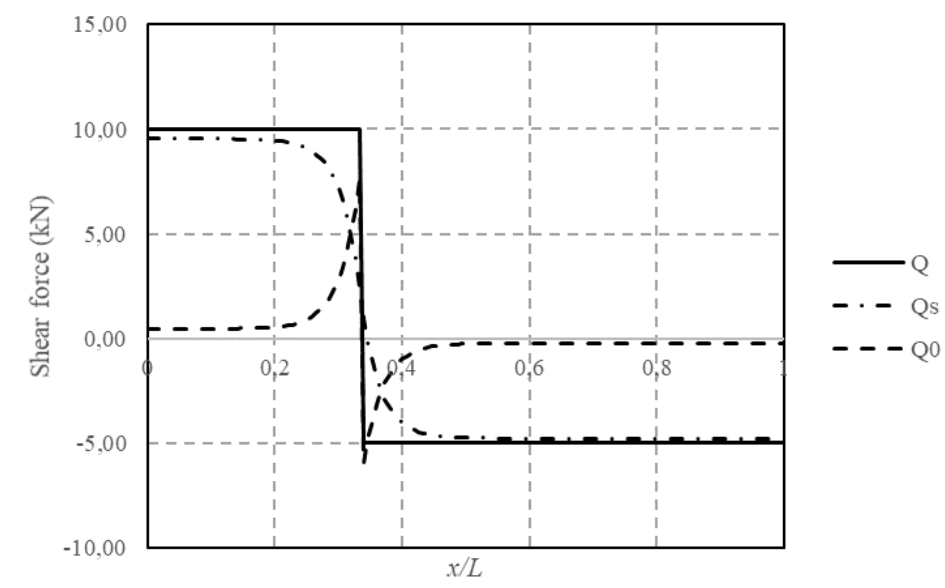

Figure 20. Shear forces with load $15 \mathrm{kN}$ of unsymmetric beam.

The maximum deflection of the beam was $10.6 \mathrm{~mm}$ using the theory of layered beams.

The FE-model was done with the data of one test in Ref. [42], 3-layers, span $1.89 \mathrm{~m}$, four-point bending, see Table 3. The half of the beam was modelled using the FEM. Rectangular four node elements were used with 5 elements per layer using the elements sizes of $7 \mathrm{~mm} \times 7 \mathrm{~mm}$, see Figure $21 \mathrm{a}$ ).

a)

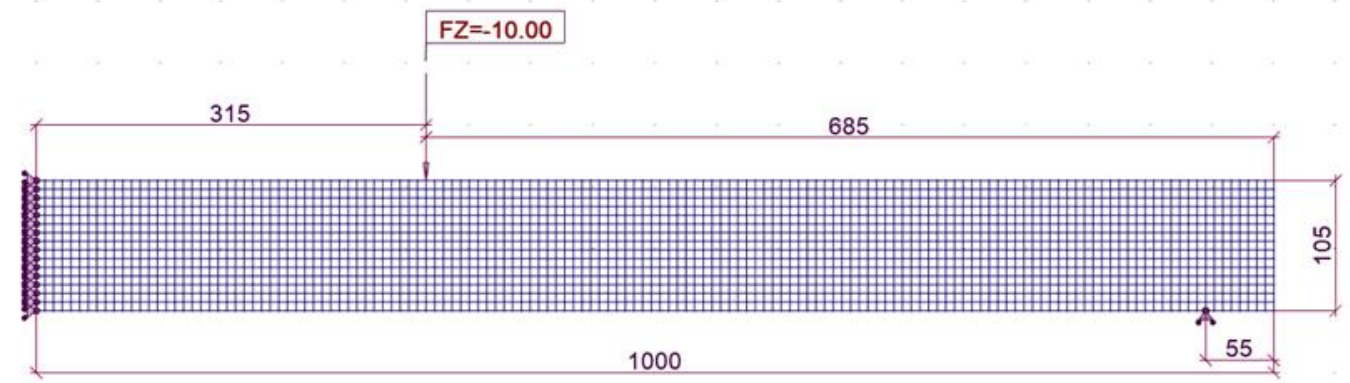

b)

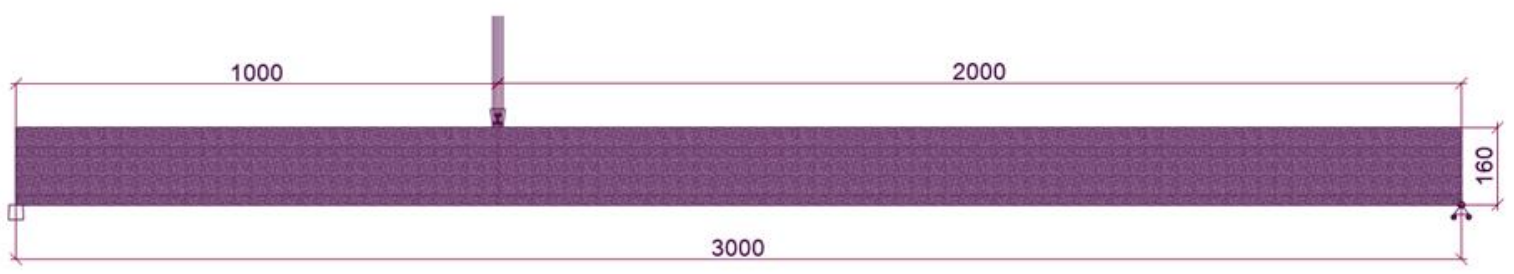

Figure 21. FEM models, a) 3-layer four point bending model, b) unsymmetric beam

The maximum deflection using the FEM was $8.3 \mathrm{~mm}$ and the axial strain of the bottom surface at the mid-span was 0.00110 extrapolated to the nodes. These values fit rather well to the measured values $8.0 \mathrm{~mm}$, and 0.00106 , respectively. The similar 
model was used for the unsymmetric beam, see Figure $21 \mathrm{~b}$ ). The element size was of 5 $\mathrm{mm} \times 5 \mathrm{~mm}$. The shear modulus of the unsymmetric beam for the parallel layers was $G_{0}$ $=690 \mathrm{MPa}$ and the Poisson' ratio in both FEM cases was 0.3 both in the parallel direction and in the transverse direction. The concentrated load $15 \mathrm{kN}$ was given as five nodal loads $3 \mathrm{kN}$ each, distributed to $20 \mathrm{~mm}$ at the top surface, to prevent the high local stresses at the loading point.

The maximum deflection using the theory of layered beams was $10.6 \mathrm{~mm}$ and using the FEM $9.6 \mathrm{~mm}$. The axial stresses at the loading point are given in Figure 22.

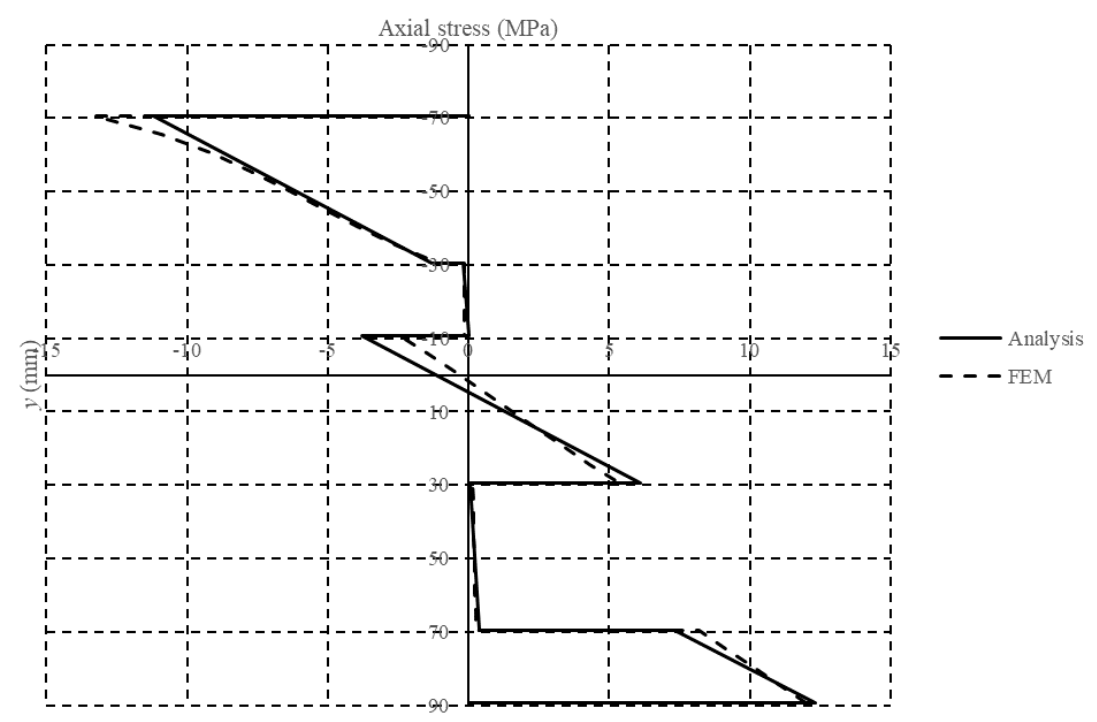

Figure 22. Axial stresses at load point of unsymmetric beam at the loading point.

In Figure 22 can be seen, that the axial stresses at the lower part of the cross-section fit rather well using the theory of layered beams to the FEM results, the maximum tensile stresses being $12.3 \mathrm{MPa}$ and 12.0, respectively. Using the FEM, the stresses of the top surface are larger due to the stress concentration near the loading point.

A refined mesh (FEM_2) using the element size of $2.5 \mathrm{~mm} \times 2.5 \mathrm{~mm}$ was used, too. The concentrated load was given as 9 nodal loads distributed to $20 \mathrm{~mm}$. Displacements and axial stresses did not change compared the results using the element size of $5 \mathrm{~mm} \mathrm{x}$ $5 \mathrm{~mm}$. The shear stresses of the FEM are taken $10 \mathrm{~mm}$ from the theoretical point load, i.e., at the section where the last nodal force is acting. 


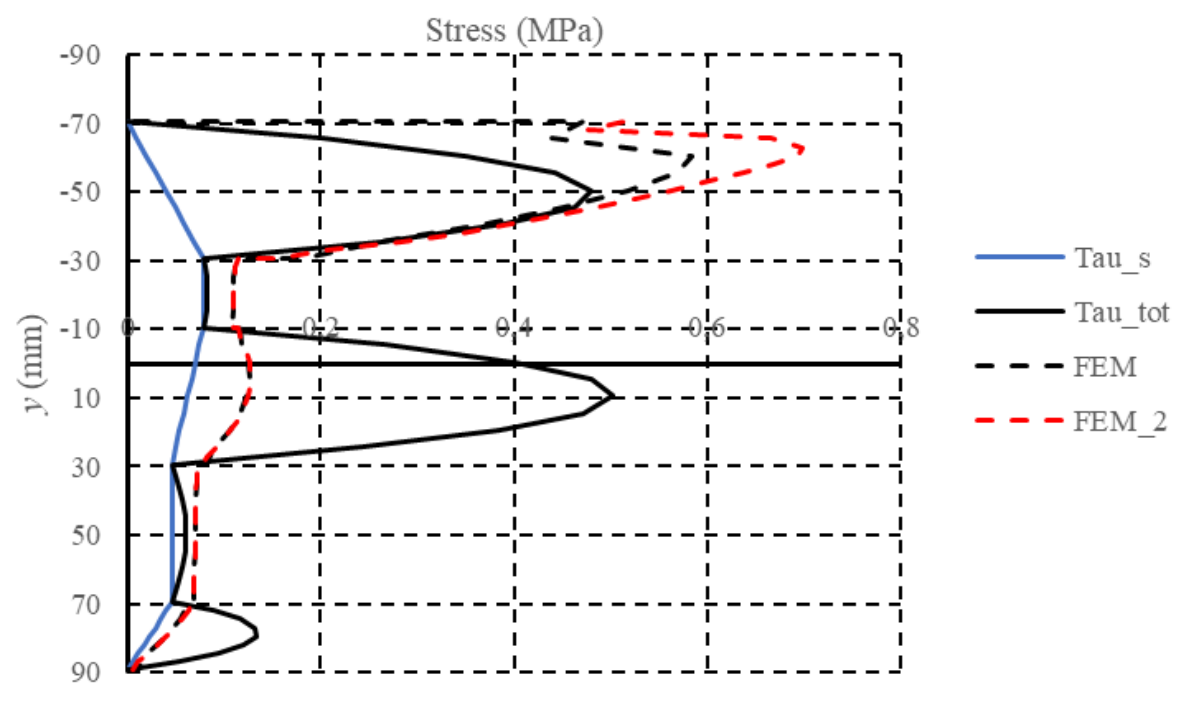

Figure 23. Shear stresses at load point of unsymmetric beam at the loading point, left side.

The mesh size had a considerable effect to the shear stresses near the top surface, as can be seen in Figure 23, FEM_2. The shear stresses of other layers did not change when changing from FEM to FEM_2. The shear stresses in the transverse direction are near FEM results using the theory of layered beams, but the shear stresses of two lowest parallel layers are larger than FEM results.

The theory of layered beams gives the values of the considered design properties, when comparing to the FEM results, to the same range of validity than those, which are compared to the test values in Table 3.

\section{Conclusions}

The classical elastic theory of layered beams is used for the analysis of the CLT beams. The introduction of the theory is given including the governing differential equations and the boundary conditions. One solution of the differential equation is given for the simply supported beam with the concentrated load. The results of the numerical examples are given, and the comparisons are done with the test results and with the FEM results.

The ratios of the calculated maximum deflections to the observed test values are in the mean 1.10 in 18 cases. The minimum ratio is 0.98 and the maximum ratio is 1.29 . When considering the design, the deflection based on the theory of layered beams is on the safe side in almost all 18 cases. The calculated axial strains are also near by the tested values. One beam with the unsymmetric cross-section was modeled using the plane stress FE-model. The calculated deflections and the maximum axial stresses were near by the FEM results. The shear stresses in the transverse direction were near by the FEM results. The shear stresses of the parallel layers were larger than the results given by the FEM analysis, but at the top layer due to the stress concentration near the point load. 
It was shown that the Shear Analogy and the theory of layered beams include the same differential equation, which means that their theoretical bases are same, although the derivations of the methods are quite different. The comparisons, which are available in the literature dealing with reliability of the Shear Analogy, the Gamma Theory and the Timoshenko theory in the analysis of the CLT beams, can be used to comparisons by compensating the Shear Analogy by the theory of layered beams. In Ref. [3] are analyzed many cases using the three methods including one-span and multi-span beams in different loading cases. The most reliable method in those cases compared to the FEM results was the Shear Analogy, so this is true also for the theory of layered beams.

The theory of layered beams offers a widely studied, well established method for the analysis the CLT beams at the elastic phase including displacements and stresses of each layer of the beam. A lot of analytical solutions can be found in the literature, and more can be computed using the related exact finite element formulations. The authors consider the theory of layered beams more straightforward in practical applications than the Shear Analogy.

\section{References}

[1] V. Bajzecerova, M. Kovac, J. Kanocz. Structural analysis of cross-laminated timber slabs subjected to bending - state of the art. SSP- Journal of Civil Engineering, Vol. 13(1): 133-140, 2018. DOI 10.1515/sspjce-2018-0027

[2] H. Blass, R. Görlacher. Rolling shear in structural bonded timber elements. International Conference on Wood and Wood Fiber Composites. Vol 5: 1-5, 2000.

[3] T. Borgensperger, G. Silly, G. Schickhofer. Comparison of methods of approximate verification procedures for cross laminated timber. Research Report, holz.bau forschungs gmbh, Graz, 2012.

[4] E. Borgström, J. Fröbel (Eds.). The CLT Handbook, CLT structures - facts and planning. Swedish Wood, 2019. ISBN 978-91-983214-4-3

[5] R. Brandner, G. Flatscher, A. Ringhofer, G. Schickhofer, A. Thiel. Cross laminated timber (CLT): overview and development. Eur. J. Wood Prod. 74: 331-351, 2016. DOI 10.1007/s00107-015-0999-5

[6] D. Buck, X. Wang, O. Hagman, A. Gustafsson. Bending Properties of Cross Laminated Timber (CLT) with a $45^{\circ}$ Alternating Layer Configuration. BioResources 11(2): 4633-4644, 2016. DOI 10.15376/biores.11.2.4633-4644

[7] K. Buka-Vaivade, D. Serdjuks, V. Goremikins, A. Vilguts, L. Pakrastins. Experimental verification of design procedure for elements from cross-laminated timber. Procedia Engineering 172: 1212-1219, 2017. DOI 10.1016/j.proeng.2017.02.142

[8] C. Ceallaigh, K. Sikora, A. Harte. The Influence of Panel lay-up on the Characteristic Bending and Rolling Shear Strength of CLT. Buildings 8(114), 2018. DOI 10.3390/buildings8090114

[9] L. Chitty. On the cantilever composed of a number of parallel beams interconnected by cross bars. Phil. Mag. Series 7, 38(285): 685-699, 1947.

[10] Y-H. Chen. General dynamic-stiffness matrix of a Timoshenko beam for transverse vibrations. Earthquake Engineering and Structural Dynamics 15: 391-402, 1987. 
[11] I. Christovasilis, M. Brunetti, M. Follesa, M. Nocetti, D. Vassallo. Evaluation of the Mechanical Properties of Cross Laminated Timber with Elementary Beam Theories. Construction and Building Materials. September 2016. DOI 10.1016/j.conbuildmat.2016.06.082

[12] R. Clough, J. Penzien. Dynamics of Structures. New York, McGraw-Hill Inc, 1975.

[13] J. Davies. Lightweight Sandwich Construction. Wiley, 2001.

[14] DIN EN 1995-1-1/NA. National Annex-Nationally determined parameters Eurocode 5: Design of timber structures - Part 1-1: General - Common rules and rules for buildings. Deutsches Institut für Normung. DIN, 2013.

[15] DIN 1052:2004-08. Entwurf, Berechnung und Bemessung von Holzbauwerken. Allgemeine Bemessungsregeln und Bemessungsregeln für den Hochbau. Deutsches Institut für Normung. DIN, 2004.

[16] EN 1995-1-1. Eurocode 5: Design of timber structures - Part 1-1: General Common rules and rules for buildings. European Committee for Standardization. CEN, 2014.

[17] EN 16351. Timber structures - cross laminated timber - requirements. European Committee for Standardization. CEN, 2015.

[18] EN 338 Structural timber - strength classes. European Committee for Standardization. CEN, 2009.

[19] S. Gagnon, C. Pirvu (Eds.). CLT Handbook: cross-laminated timber. Canadian Edition. 2011. ISBN 978-0-86488-547-0

[20] H. Granholm. Om sammansatta balkar och pelare med särskild hänsyn till spikade träkonstruktioner (On composite beams and columns with particular regard to nailed timber structures). Transactions of Chalmers University of Technology, No. 88. Göteborg, 1949.

[21] D. Green, J. Winandy, D. Kretschmann. Mechanical Properties of Wood. Wood handbook - Wood as an engineering material. Forest Products Laboratory: 4-1 4-45, 1999.

[22] M. He, X. Sun, Z. Li, W. Feng. Bending, shear, and compressive properties of three- and five-layer cross-laminated timber fabricated with black spruce. Journal of Wood Science 66:38, 2020. DOI 10.1186/s10086-020-01886-z

[23] M. Heinisuo, An exact finite element technique for layered beams. Computers \& Structures Vol 30. No. 3. 615-622, 1988.

[24] M. Heinisuo. Exact Finite Element Method for Layered Beams. Publications 56, Tampere University of Technology, Tampere, 1989.

[25] N. Hoff, S. Mautner. Bending and buckling of sandwich beams. Journal of the Aeronautical Sciences 15(12): 707-720, 1948.

[26] R. Itani, G. Hiremath. Partial composite action in diaphragms. Journal Engineering Mechanics Division. Proceedings of the ASCE 106(EM4): 739-751, 1980.

[27] M. Jelec, D. Varevac, V. Rajcic. Cross-laminated timber (CLT) - A state of the art report. Gradevinar 70(2):75-95, 2018. DOI 10.14256/jce.2071.2017

[28] E. Karacabeyli, B. Douglas. CLT Handbook: cross-laminated timber. US Edition. 2013. ISBN 978-0-86488-553-1

[29] K-M. Kin, K-B. Shim. Comparison between tensile and compressive Young's modulus of structural size lumber. $11^{\text {th }}$ World Conference on Timber Engineering. Trentino, Italy. WCTE, 2010. 
[30] G. Kitazawa. Young's modulus of elasticity by dynamic measurements. For. Prod. J., 2(5): 228-231, 1952.

[31] H. Kreuzinger. Flächentragverke - Platten, Scheiben und Schalen Berechnungsmethoden und Beispiele. Fachverlag Holz. Dusseldorf, 1999.

[32] B. Madson, A. Buchannan. Size effects in timber explained by a modified weakest link theory. Canadian Journal of Civil Engineering. Vol 13(2): 218-232, 1986.

[33] S. Malmi. Kaksipaarteisen Sandwich-palkin tarkka dynaaminen analyysi elementtimenetelmällä (Exact dynamic analysis of two-faced sandwich beam using finite element analysis). Master thesis. Tampere University of Technology, Tampere, 1987.

[34] J-P. Matilainen, J. Puttonen. Free vibration of CLT plates. Rakenteiden Mekaniikka. Vol 47(1): 17-33, 2014.

[35] P. Mestek, H. Kreuzinger, S. Winter. Design of Cross Laminated Timber (CLT). $10^{\text {th }}$ World Conference on Timber Engineering. Miyazaki, Japan. WCTE, 2008.

[36] K. Möhler. Über das Tragverhalten von Biegeträgern und Druckstäben mit zusammengesetzten Querschnitten und nachgiebigen Verbindungsmitteln. Habilitation: Technische Universität Karlsruhe, Germany, 1956.

[37] A. Möttönen. Kaksipaarteisen sandwich-palkin tarkka elementtimenetelmä taivutuspuristuksessa ja lämpökuormituksessa (Exact finite element method of two-faced sandwich beam in bending/compression and in thermal loading). Master thesis. Tampere University of Technology. Tampere, 1987.

[38] H. Parland. Yhdistettyjen puukannattajien lujuus (Strength of composite wooden structures). Helsinki, 1946.

[39] H. Parland. Rakennustatiikan sovellutuksia (Applications of building static). Tampere University of Technology, Tampere, 1972.

[40] P. Pleskov. Teoriia rascheta dereviannykh sostavnnykh sterzhnei (Theoretical studies of composite wood structures). Moscow, 1952.

[41] R. Rosman. Die statische Berechnung von Hochhauswänden mit Öffnunsreihen. Bauingenieur-Praxis. Heft 65, Berlin, Verlag von Wilhelm Ernst \& Sohn, 1965.

[42] G. Ruan, H. Xiong, J. Chen. Bending and Rolling Shear Properties of CrossLaminated Timber Fabricated with Canadian Hemlock. SDHM. Vol 13(2): 227246, 2019. DOI 10.32604/shdm.2019.04743

[43] G. Schickhofer, T. Bogensperger, T. Moosbrugger (Eds.). BSPhandbuch: HolzMassivbauweise in Brettsperrholz-Nachweise auf Basis des neuen europäischen Normenkonzepts. Verlag der Technischen Universität Graz. Graz, 2010.

[44] A. Silker. Young's modulus parallel to the grain in wood as a function of strain rate, stress level and mode loading. WOOD AND FIBER. Michigan Agricultural Experiment Station Journal, Article Number 6133: 325-333, 1972.

[45] K. Stamm, H. Witte. Sandwichkonstruktionen. Berechnung, Fertigung, Ausführung. Springer-Verlag, Wien, New York, 1974.

[46] E. Thompson, J. Goodman, M. Vanderbilt. Finite element analysis of layered wood systems. Journal of Structural Division. Proceedings of the ASCE 101(ST12): 2659-2671, 1975.

[47] S. Timoshenko. On the correction factor for shear of the differential equation for transverse vibrations of bars of uniform cross-section. Phil. Mag. 41: 744-746, 1921. 
[48] M. Wallner-Novak, J. Koppelhuber, K. Pock. Brettperrholz Bemessung Grundlagen für Statik und Konstruktion nach Eurocode. proHolzAustria. Vienna, 2013.

[49] C. Zhang, G. Lee, F. Lam. Connection and performance of two-way CLT plates. UBC TEAM Report: TEAM 2017-08, University of British Columbia, Vancouver, Canada, 2018.

[50] ÖNORM B 1995-1-1/NA. Eurocode 5: Design of timber structures - Part 1-1:

General - Common rules and rules for buildings - national specifications, national comments and national supplements concerning ÖNORM EN 1995-1-1. Austrian Standards Institute. ASI, 2014.

Markku Heinisuo, Sami Pajunen

Unit of Civil Engineering, Tampere University

P.O. BOX 600, 33014 Tampere University Finland

markku.heinisuo@tuni.fi,sami.pajunen@tuni.fi 


\section{Appendix A. Shear Analogy}

At the turn of the last millennium Kreuzinger Ref. [31] designed a calculation method called the Shear Analogy. The Shear Analogy is based on the following assumptions:

1. The structural behavior is presented by two overlapping beams which are coupled by the common deflection.

2. The bending stiffness of beam A corresponds with the moments of inertia of the layers, whereas the beam B corresponds with the Steiner terms.

3. Beam A is supposed to be rigid in shear, while the shear flexibility of the beam $B$ results from the flexibility of the cross-layers.

The physical interpretation of the method is: Two beams $\mathrm{A}$ and $\mathrm{B}$ which are connected with vertical hinge-ended stiff bars located infinitely densely.

The differential equation of the beam A is got from Eq. (2) by setting the shear factor $k$ to infinity and setting the bending stiffness as $B_{0}$. The result is

$$
B_{0} v^{(4)}=p-q,
$$

where $q$ is the load distribution of the connecting vertical bars. The differential equation of the beam B is got from Eq. (2) by setting $B_{0}=0$. The result is

$$
B_{s} k v^{(4)}=k q-B_{s} q^{(2)} \text {. }
$$

Solving the function $q$ from Eq. (A.1) and substitution to Eq. (A.2) leads to the sixth order differential equation (2). It can be concluded that the theory of the Shear Analogy is the same as the theory of layered beams. This conclusion has not been found in the literature.

The differential equations (A.1) and (A.2) are solved as coupled. Analytical solutions are given in Ref. [A1]. Numerical solutions are given based on the physical interpretation given above. The beam $\mathrm{A}$ and the beam $\mathrm{B}$ are modelled using a plane frame program by setting the distance of vertical bars short enough Ref. [3].

\section{Appendix A reference}

[A1] A. Scholz. Ein Beitrag zur Berechnung von Flächentragwerken aus Holz. Dissertation TU München, 2004. 


\section{Appendix B. Shear Factor}

Consider rotations of the layered beam in Figure B.1.

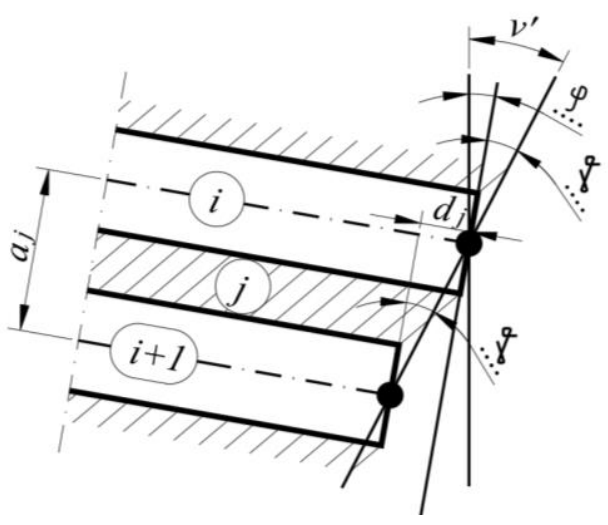

Figure B.1. Rotations of the layered beam.

The slip $d_{j}$ at the level of the centroids of the faces $i$ and $i+1$ is

$$
d_{j}=\gamma a_{j} .
$$

It is supposed that the core resists linearly this slip and the shear stiffness intensity of the core is $k_{j}$, so the shear flow $T_{j}$ of the core is

$$
T_{j}=k_{j} d_{j}=k_{j} a_{j} \gamma .
$$

Consider next the free body diagram of the length $d x$ in Figure B.2.

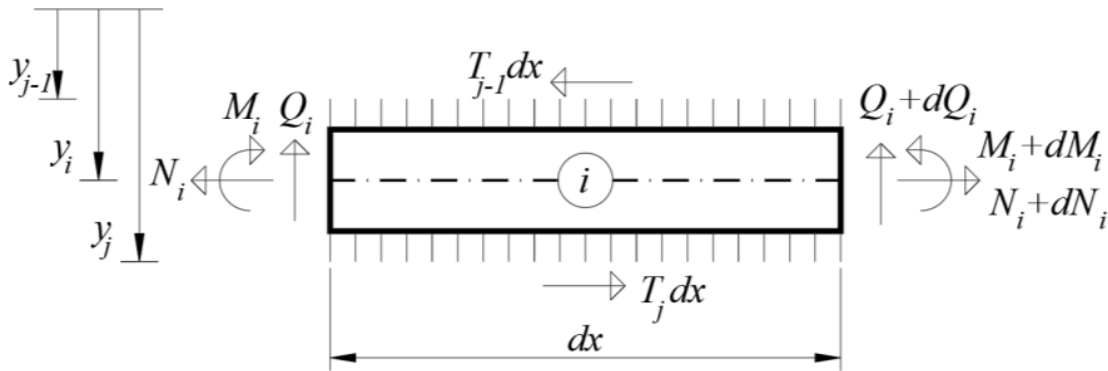

Figure B.2. Free body diagram.

The moment equilibrium implies

$$
Q_{i}=M_{i}^{r}+T_{j}\left(y_{j}-y_{i}\right)+T_{j-1}\left(y_{i}-y_{j-1}\right) .
$$

By assuming that there is no longitudinal surface loading summation of equations (B.3) gives 


$$
Q=\sum_{i=1}^{n} Q_{i}=\sum_{i=1}^{n} M_{i}^{r}+\sum_{j=1}^{n-1} a_{j} T_{j}
$$

The faces are acting as Bernoulli-Euler beams so $M_{i}=-E_{i} I_{i} v^{\text {'" }}$ and the shear flow $T_{j}$ is following (B.2), then

$$
Q=-\sum_{i=1}^{n} E_{i} I_{i} v^{\prime \prime \prime}+\sum_{j=1}^{n-1} a_{j}^{2} k_{j} \gamma=-B_{0} v^{\prime \prime}+k \gamma,
$$

where is used the notation (11) for the shear factor $k$. 


\section{Appendix C. 3- and 5-layer beams using Timoshenko Theory}

Consider the maximum deflections of 3- and 5-layer short and long beams, see Figure 3. The maximum deflections are calculated using the equation of the virtual work

$$
v\left(\frac{L}{2}\right)=\int_{0}^{L} \frac{M_{1}(x) M_{2}(x)}{B} d x+\int_{0}^{L} \frac{Q_{1}(x) Q_{2}(x)}{\kappa G A} d x
$$

where $M_{1}$ and $Q_{1}$ are the moment and the shear force of the load and $M_{2}$ and $Q_{2}$ are the moment and the shear force of the unit load at the mid-span of the beam, $L$ is the span of the beam, $B$ is the bending stiffness of the beam and $\kappa G A$ is the shear stiffness of the beam considering all layers. The shape factor $\kappa=0.2$ is used for the layers of the CLT beams Refs. [4], [11].

The maximum deflection of the long beam with the total load $F$ is

$$
v\left(\frac{L}{2}\right)=\frac{F a\left(3 L^{2}-4 a^{2}\right)}{48 B}+\frac{F(L-2 a)}{8 \kappa G A}
$$

and for the short beam

$$
v\left(\frac{L}{2}\right)=\frac{F L^{3}}{48 B}+\frac{F L}{4 \kappa G A}
$$

The data of the calculations is shown in Table C.1.

Table C.1. Data of the Timoshenko theory.

\begin{tabular}{|l|c|c|c|c|}
\hline Property & $\begin{array}{c}\text { Long 3-layer } \\
\text { beam }\end{array}$ & $\begin{array}{c}\text { Long 5-layer } \\
\text { beam }\end{array}$ & $\begin{array}{c}\text { Short 3-layer } \\
\text { beam }\end{array}$ & $\begin{array}{c}\text { Short 5-layer } \\
\text { beam }\end{array}$ \\
\hline$L(\mathrm{~mm})$ & 3195 & 4645 & 575 & 845 \\
\hline$a(\mathrm{~mm})$ & 1282.5 & 1857.5 & 287.5 & 422.5 \\
\hline$F(\mathrm{kN})$ & 13.49 & 14.8 & 30 & 60 \\
\hline$b_{i}=b_{j}(\mathrm{~mm})$ & 310 & 310 & 310 & 310 \\
\hline Height of layers $(\mathrm{mm})$ & $35 / 35 / 35$ & $35 / 25 / 35 / 25 / 35$ & $35 / 35 / 35$ & $35 / 25 / 35 / 25 / 35$ \\
\hline$E_{0}\left(\mathrm{~N} / \mathrm{mm}^{2}\right)$ & 10925 & 10925 & 10925 & 10925 \\
\hline$E_{90}\left(\mathrm{~N} / \mathrm{mm}^{2}\right)$ & 993 & 993 & 993 & 993 \\
\hline$G_{0}\left(\mathrm{~N} / \mathrm{mm}^{2}\right)$ & 683 & 683 & 683 & 683 \\
\hline$G_{90}\left(\mathrm{~N} / \mathrm{mm}^{2}\right)$ & 68.3 & 68.3 & 68.3 & 68.3 \\
\hline$B(\mathrm{Nmm})$ & $3.157 \mathrm{E}+11$ & $9.044 \mathrm{E}+11$ & $3.157 \mathrm{E}+11$ & $9.044 \mathrm{E}+11$ \\
\hline$\sum \kappa_{j} G_{j} A_{j}(\mathrm{~N})$ & 148211 & 211730 & 148211 & 211730 \\
\hline$v(L / 2)$ bending $(\mathrm{mm})$ & 27.5 & 32.3 & 0.4 & 0.8 \\
\hline$v(L / 2)$ shear $(\mathrm{mm})$ & 0.3 & 0.4 & 1.4 & 2.7 \\
\hline$v(L / 2)$ total $(\mathrm{mm})$ & 27.8 & 32.6 & 1.8 & 3.6 \\
\hline
\end{tabular}

